\title{
La cronología radiocarbónica de las primeras manifestaciones megalíticas en el sureste de la Península Ibérica: las necrópolis de Las Churuletas, La Atalaya y Llano del Jautón (Purchena, Almería)*
}

\author{
The radiocarbon chronology of the oldest megalithic monuments in southeastern Iberia: \\ the necropolises of Las Churuletas, La Atalaya and Llano del Jautón (Purchena, Almería)
}

\author{
Gonzalo Aranda Jiméneza , Águeda Lozano Medina ${ }^{a}$, María Dolores Camalich Massieu ${ }^{\mathrm{b}}$, \\ Dimas Martín Socas ${ }^{\mathrm{b}}$, Francisco Javier Rodríguez Santos ${ }^{\mathrm{c}}$, Aioze Trujillo Mederos ${ }^{\mathrm{b}}$, \\ Jonathan Santana Cabrera ${ }^{d}$, Angelique Nonza-Micaelli ${ }^{e}$ y Xavier Clop García ${ }^{f}$
}

\section{RESUMEN}

Por primera vez en el estudio del fenómeno megalítico del sureste de la Península Ibérica se ha obtenido una serie radiocarbónica para el análisis de sus manifestaciones más antiguas. Se han datado 30 restos antropológicos de sepulturas tipo rundgräber y de tumbas de cámara y corredor pertenecientes a las necrópolis de Las Churuletas, La Atalaya y Llano de El Jautón. El análisis estadístico de esta serie radiocarbónica ha permitido establecer las siguientes conclusiones: i) el inicio de la actividad funeraria ocurriría entre el 3730-3650 cal BC y el final entre el 2395-2270 cal BC; ii) las sepulturas tipo rundgräber son las que poseen una duración más corta, finalizando entre el 2650-2505 cal BC; iii) la datación de diferentes sepulturas y necrópolis muestra una importante heterogeneidad en sus periodos de uso; y iv) a partir de principios del III milenio se produciría una significativa intensificación de la actividad funeraria paralela al incremento demográfico y desarrollo del poblamiento.

\begin{abstract}
For the first time in the study of the southeastern Iberian megalithic phenomenon, a series of 30 radiocarbon dates has been obtained for some of the oldest mon-
\end{abstract}

" El presente trabajo forma parte de los proyectos de investigación: "Todo tiene un tiempo. Cronología y temporalidad en las sociedades megalíticas del sur de la Península Ibérica" (Fundación BBVA. Ayudas a investigadores y creadores culturales 2015), "Innovación, continuidad e hibridación. Las sociedades de las Edades del Cobre y Bronce en el sur de la Península Ibérica" (HAR201342865-P) y "Tecnología y Sociedad. Las primeras artesanías de las comunidades neolíticas en Andalucía Oriental entre el VI y el III milenio ANE" (HAR2016-78197-P).

a Dpto. de Prehistoria y Arqueología. Universidad de Granada. Campus Cartuja s/n. 18071 Granada. España. Correos e.: garanda@ugr.es http://orcid.org/0000-0003-1925-0221; aguedalozanomed@gmail.com http://orcid.org/0000-0002-1696-5996.

b Dpto. de Geografía e Historia, UDI Prehistoria, Arqueología e Historia Antigua, Universidad de La Laguna. Aptdo. 456.38200 La Laguna. Tenerife. Correos e.: dmassieu@ull.edu.es http://orcid.org/0000-0001-5288-4168; dsocas@ull.edu.es; http://orcid.org/00000001-9482-426X; aiozetm@gmail.com http://orcid.org/0000-0001-7238-465.

c Instituto Internacional de Investigaciones Prehistóricas de Cantabria. Universidad de Cantabria. Avda. Los Castros 52. 39005 Santander. España. Correo e.: javirosantos@gmail.com http://orcid.org/0000-0003-1385-5289.

d Dept. of Archeology, Durham University. South Rd. DH1 3LE Durham. Reino Unido. Correo e.: jonsantana82@gmail.com http://orcid.org/0000-0002-9615-8560.

• UMR CNRS 6240 LISA. Université de Corse BP 52. 20250 Córcega. Francia. Correo e.: nonza@univ-corse.fr http://orcid. org/0000-0002-2078-5605.

${ }^{\mathrm{f}}$ Dpto. de Prehistoria. Universidad Autónoma de Barcelona. C/ de la Fortuna s/n. 08193 Bellaterra. España. Correo e.: Xavier.Clop@uab.cat http://orcid.org/0000-0002-1875-5554.

Recibido 24-III-2017; aceptado 3-V-2017. 
uments. Two types of tombs, circular chambers (rundgräber) and graves with chamber and passage, from three necropolises, Las Churuletas, La Atalaya and El Llano de El Jautón, have been dated using human remains. Four main conclusion can be drawn from the statistical analysis of this radiocarbon series: $i)$ the beginning of funeral activity occured between 3730-3650 cal BC and the end between 2395-2270 cal BC; ii) the rundgräber are the type of tomb with shorter duration, ending between 2650-2505 cal BC; iii) the dating of different graves and necropolises shows an important heterogeneity in their periods of use; and iv) from the beginning of the $3^{\text {rd }}$ millennium, there is a strong intensification of funerary activity along with an crease population size and the number of settlements.

Palabras clave: Neolítico; Edad del Cobre; Cronología; Datación radiocarbónica; Modelado Bayesiano; Sureste de la Península Ibérica.

Key words: Neolithic; Copper Age; Chronology; Radiocarbon Dating; Bayesian Modelling; South-eastern Iberia.

\section{INTRODUCCIÓN}

Los recientes avances metodológicos en las mediciones radiométricas y en su interpretación estadística están suponiendo un profundo cambio en nuestra percepción de la temporalidad de las sociedades pasadas (Buck et al. 1991; Buck et al. 1996; Bronk Ramsey 1994; Taylor 1997; Bayliss 2009; Bayliss y Whittle 2007; Whittle et al. 2011). La datación por AMS ha facilitado el uso de muestras mucho más pequeñas ampliándose de esta forma la diversidad de materiales potencialmente datables, la desviación estándar de las mediciones está disminuyendo progresivamente y el uso de herramientas como la estadística bayesiana en el análisis de series radiocarbónicas está permitiendo construir modelos cronológicos de gran precisión (Whittle et al. 2008; Whittle et al. 2011; Scarre 2010).

Las investigaciones sobre las sociedades megalíticas de la Península Ibérica no se están beneficiando de estas mejoras, al menos no de la misma manera que en otras regiones europeas. Las escasas fechas a partir de las cuales se ha intentado aproximarse a su temporalidad solo han permitido confirmar un marco cronológico general para el fenómeno megalítico. Realmente, la cronología radiocarbónica no ha ocupado un lugar preferente en las agendas de investigación hasta estos últimos años. El sureste de la Península Ibérica con solo 10 dataciones hasta 2012 es un caso paradigmático. $\mathrm{Su}$ exiguo número puede considerarse uno de los principales obstáculos para la mejor comprensión del, por otra parte complejo, fenómeno megalítico (Aranda Jiménez 2013, 2014; Lozano Medina y Aranda Jiménez 2017).

Con el propósito de contribuir a cambiar esta situación en el año 2012 iniciamos un programa de dataciones radiocarbónicas cuya formulación general puede sintetizarse en los siguientes objetivos: i) analizar la cronología y temporalidad del fenómeno megalítico; ii) determinar el periodo de construcción y uso de los diferentes tipos de sepulturas; iii) establecer la temporalidad de sepulturas megalíticas específicas para obtener una aproximación más precisa a su biografía y, iv) explorar la continuidad y reutilización de estos espacios funerarios colectivos en momentos cronológicos y culturales diferentes a los tradicionalmente considerados de construcción y uso.

Para el desarrollo de este programa de dataciones se seleccionaron necrópolis representativas de la diversidad de sepulturas megalíticas conocidas en la región, como la necrópolis de El Barranquete (Níjar, Almería), formada por sepulturas tipo tholos o de falsa cúpula, cuyos resultados han sido recientemente publicados (Aranda Jiménez y Lozano Medina 2014; DíazZorita et al. 2016; Aranda Jiménez et al. 2017a). Otra es la necrópolis de Panoria (Darro, Granada) consistente en tumbas ortostáticas de corredor excavadas en 2015 por nuestro grupo de investigación (Benavides et al. 2016; Aranda Jiménez et al. 2017b) y, finalmente, varias necrópolis de sepulturas, en su mayoría de tipo rundgräber, agrupadas en el denominado como "Grupo Purchena" (Almería). Precisamente, el objetivo del presente trabajo es analizar y discutir la serie radiocarbónica obtenida para este último tipo de sepulturas tradicionalmente vinculadas a época neolítica a partir de las características tipológicas de su cultura material. Para ello, se presenta en primer lugar las características generales del "Grupo Purchena" y de las sepulturas objeto de estudio. Después se valora la serie radiocarbónica obtenida y, finalmente, se discuten los resultados en el contexto de la cronología del Neolítico y Edad del Cobre de la región. 


\section{EL GRUPO PURCHENA Y LAS SEPULTURAS TIPO RUNDGRÄBER}

Las excavaciones realizadas por Luis Siret y Pedro Flores, a finales del siglo XIX principios del $\mathrm{XX}$, son el punto de partida para el conocimiento del fenómeno megalítico como para otros tantos aspectos culturales de la Prehistoria Reciente del sureste peninsular. Estos trabajos siguen formando la base documental esencial para su estudio, aunque George y Vera Leisner (1943) publicaran y sistematizaran la información en su gran obra Die Megalithgräber der Iberischen Halbinsel: Der Süden. Precisamente en ella se define por primera vez el denominado "Grupo Purchena", formado por las necrópolis megalíticas de Las Churuletas ${ }^{1}$, La Atalaya, Llano del Jautón, Llano de la Lámpara, Barranco del Jocalla y Buena Arena (Fig. 1), así como la sepultura del tipo denominado rundgräber consistente en tumbas de cámara circular sin corredor de acceso y estructura tumular.

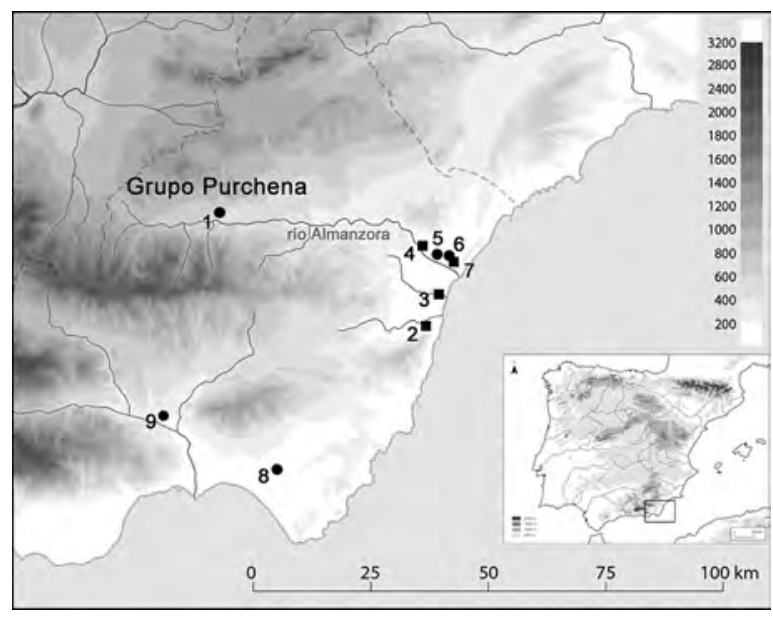

Fig. 1. Localización en el sureste de la Península Ibérica (provincia de Almería) de los principales yacimientos mencionados en el texto: 1. Grupo Purchena; 2. Las Pilas (Mojácar); 3. Cabecicos Negros (Vera); 4. Campos, 5. Cerro Virtud, 6. La Encantada 1 y 7. Almizaraque (Cuevas del Almanzora); 8. El Barranquete (Níjar); 9. Los Millares (Santa Fé de Mondújar).

\footnotetext{
1 También denominado en la bibliografía especializada como Los Churuletes y Los Turuletes.
}

Desde entonces, los rundgräber caracterizaron el Grupo Purchena, aunque no es el único: también se documentaron tumbas de corredor con cámara circular y quizás sepulturas con cubierta de falsa cúpula o tholoi (véase discusión más adelante). En la organización secuencial de los diferentes tipos de sepulturas, siguiendo a Luis Siret, George y Vera Leisner situaron los rundgräber en las Fases I y II, las más antiguas, adscribiéndolos dentro de la época neolítica, a la Cultura de Almería definida por Pedro Bosch Gimpera (1932, 1944, 1969). Con algunos matices, esta propuesta cronológica se ha mantenido hasta la actualidad. Se acepta una cierta evolución o al menos sucesión temporal entre las sepulturas de época neolítica, caracterizadas por su sencillez arquitectónica como los rundgräber o las tumbas de planta rectangular y cuadrangular, y las tumbas tipo tholoi de la Edad del Cobre de mayor complejidad estructural (Chapman 1991; Guilaine 1996; Cámara y Molina 2004).

Tras las excavaciones de Luis Siret y Pedro Flores, solo hubo intervenciones en la necrópolis de Las Churuletas en 1973 aunque con resultados exiguos. La nueva excavación de varias sepulturas básicamente constató el alto grado de destrucción que ya en aquel entonces presentaban (Olaria 1977). La investigación más reciente se ha centrado en el estudio de los restos materiales y cuadernos de excavación y manuscritos de Luis Siret y Pedro Flores depositados en el Museo Arqueológico Nacional de Madrid (MAN). Para el caso del "Grupo Purchena", destaca la caracterización de los conjuntos cerámicos a cargo del equipo de investigación de la Universidad de la Laguna (Camalich Massieu 1983; Camalich Massieu et al. 1989; Martín Socas et al. 1989) y, para el caso específico de la necrópolis de Las Churuletas, el estudio tipológico y comparativo de sus ajuares funerarios (Peña y Montes de Oca 1986).

Los trabajos más recientes se deben a Ruth Maicas (1997, 2005, 2007; Maicas y Papí 2008), quien ha revisado y catalogado de modo exhaustivo los materiales y el registro documental de la denominada Colección Siret. Estas investigaciones han sido el punto de partida de un excelente trabajo sobre la industria ósea de época neolítica y calcolítica en la cuenca de Vera (Maicas 2007). En lo que respecta a las necrópolis del "Grupo Purchena" analiza las discrepancias existentes entre los diferentes registros documentales y entre 
estos y los restos materiales conservados en el MAN. Esta discusión es de enorme relevancia dado que permite identificar qué sepulturas presentan errores en la adscripción de materiales y las posibles mezclas y pérdidas resultantes de la compleja biografía de la Colección Siret.

La discusión cronológica basada en las características tipológicas de los ajuares funerarios de las sepulturas del "Grupo Purchena" ha sido la línea de investigación más ampliamente desarrollada. Las propuestas han oscilado entre dos extremos. Unas han intentado secuenciar la denominada "Cultura de Almería" en fases a las que les corresponderían elementos de ajuar y tipos de sepulturas específicos (Leisner y Leisner 1943; Blance 1961). Otras han defendido la contemporaneidad de los rundgräber con las sepulturas de falsa cúpula a partir de la presencia en las primeras de objetos característicos de la Edad del Cobre, caso de objetos metálicos, puntas de flecha y hojas de sílex entre otros (Acosta y Cruz-Auñón 1981; Olaria 1977). Ambas propuestas no son excluyentes, de hecho diferentes autores/as han enfatizado precisamente la enorme perduración temporal de este fenómeno (Peña y Montes de Oca, 1986; Lorrio y Montero 2004; Maicas 2007), con episodios de reutilización durante la Edad del Bronce, como el documentado en la tumba 8 de la necrópolis de La Atalaya (Lorrio 2008).

El debate cronológico a partir de la tipología de los ajuares posee algunas limitaciones dignas de considerar. La principal es el carácter de palimpsesto de estas construcciones donde, por su carácter colectivo, pueden convivir deposiciones rituales alejadas temporal y culturalmente. Las potenciales prácticas que supongan la retirada de restos antropológicos y/o ajuares previos o la deposición de materiales antiguos procedentes de otros sitios añaden un mayor grado de complejidad. Además en diferentes sepulturas megalíticas se han registrado deposiciones de restos antropológicos en momentos culturales sin elementos de ajuar relacionables. Así lo confirmarían las dataciones radiocarbónicas obtenidas sobre hueso humano en sepulturas como La Loma de la Gorriquía 1, Las Alparatas 1, Qurénima (Lorrio y Montero 2004) y las tumbas 8, 9, 10 y 11 de la necrópolis de El Barranquete (Aranda Jiménez y Lozano Medina 2014; Aranda Jiménez et al. 2017a). Establecer, por tanto, el periodo de uso de una determinada tumba o la sucesión o con- temporaneidad de diferentes tipos de sepulturas requiere de programas de dataciones radiocarbónicas que permitan superar las limitaciones del análisis tipológico.

\section{LAS NECRÓPOLIS DE LAS CHURULETAS, LA ATALAYA Y LLANO DEL JAUTÓN}

Del conjunto de necrópolis que forman el denominado Grupo Purchena se han seleccionado para datación radiocarbónica Las Churuletas, La Atalaya y el Llano del Jautón. Ello se debe, primero, a que son las necrópolis más intensamente investigadas desde los trabajos de Luis Siret y Pedro Flores (Olaria 1977; Peña y Montes de Oca 1986; Maicas 1997) y, en segundo lugar, a que agrupan a un número significativo de sepulturas representativas de la diversidad de tipos de construcciones megalíticas, muy especialmente rundgräber.

En total se documentaron 27 sepulturas: 6 pertenecen a la necrópolis de Las Churuletas, 14 a La Atalaya y 7 al Llano del Jautón. El tipo dominante es el de los rundgräber (23 tumbas), registrado en las tres necrópolis. Estas sepulturas de planta circular suelen estar construidas con mampostería y/o losas de piedra (normalmente pizarra) y a veces presentan sus pavimentos enlosados (Tab. 1). Las dimensiones más frecuentes oscilan entre los 2 y $4 \mathrm{~m}$ de diámetro y entre 0,30 y $1,50 \mathrm{~m}$ de profundidad. Hay casos extremos de solo $1 \mathrm{~m}$ de diámetro, como la tumba 6 de Las Churuletas, o de 5,5 m como La Atalaya 3. En las nuevas excavaciones de la necrópolis de Las Churuletas se documentaron varias estructuras tumulares de ca. $5 \mathrm{~m}$ de diámetro (Olaria 1977).

El segundo tipo de sepultura, presente también en las tres necrópolis, se corresponde con 4 tumbas de planta circular y corredor de acceso. La cámara funeraria mide entre 2,70 y $4 \mathrm{~m}$ de diámetro y los corredores entre 1 y $2 \mathrm{~m}$ de longitud. Finalmente, se ha planteado que hubiera tholoi o sepulturas de falsa cúpula en la necrópolis del Llano del Jautón. George y Vera Leisner (1943) identificaron como tholos la sepultura 6, la única tumba de corredor de esta necrópolis. Sin embargo para Ruth Macias (2007) solo la tumba 5b podría haber estado cubierta con falsa cúpula, dadas

Trab. Prehist., 74, N. ${ }^{\circ}$ 2, julio-diciembre 2017, pp. 257-277, ISSN: 0082-5638

doi: $10.3989 /$ tp.2017.12194 
La cronología radiocarbónica de las primeras manifestaciones megalíticas en el sureste de la Península Ibérica... 261

\begin{tabular}{|c|c|c|c|c|c|c|c|}
\hline Sepultura & Tipo & $\begin{array}{l}\text { Dimensiones } \\
\text { según Pedro } \\
\text { Flores }\end{array}$ & $\begin{array}{l}\text { Material de } \\
\text { construcción }\end{array}$ & $\begin{array}{l}N^{\circ} \text { restos según } \\
\text { Pedro Flores }\end{array}$ & NMI & $\begin{array}{l}\text { Muestras } \\
\text { selecc. }\end{array}$ & $\begin{array}{c}\text { Muestras } \\
\text { datadas }\end{array}$ \\
\hline \multicolumn{8}{|c|}{ LAS CHURULETAS } \\
\hline Sepultura 1 & Rundgräber & $3,5 \mathrm{~m} \varnothing$ & $\begin{array}{l}\text { Mampostería y } \\
\text { ortostatos }\end{array}$ & $\begin{array}{l}\text { "Restos de muchos } \\
\text { esqueletos" }\end{array}$ & 1 (fauna) & 1 & 1 \\
\hline Sepultura 2 & Rundgräber & $2,5 \mathrm{~m} \varnothing$ & - & "Restos de esqueletos" & 3 & 1 & 1 \\
\hline Sepultura 3 & Rundgräber & $3 \mathrm{~m} \varnothing$ & 16 losas pizarra & $\begin{array}{l}\text { "Restos de } 50 \\
\text { esqueletos" }\end{array}$ & 13 & 3 & 3 \\
\hline Sepultura 4 & $\begin{array}{l}\text { Cámara y } \\
\text { corredor }\end{array}$ & $\begin{array}{l}\text { Cámara: } 4 \mathrm{~m} \varnothing \\
\text { Corredor } 2 \mathrm{~m} \\
\end{array}$ & Losas pizarra & "Restos de esqueletos" & 4 & 3 & 2 \\
\hline Sepultura 5 & Rundgräber & $2,8 \mathrm{~m} \varnothing$ & - & "Restos de esqueletos" & 8 & 1 & 1 \\
\hline Sepultura 6 & Rundgräber & $1 \mathrm{mø}$ & - & "Restos de esqueletos" & 5 & 1 & 1 \\
\hline \multicolumn{8}{|c|}{ LA ATALAYA } \\
\hline Sepultura 1 & Rundgräber & $2,50 \times 2,30 \mathrm{~m} \varnothing$ & 11 ortostatos & - & 3 & 1 & 1 \\
\hline Sepultura 2 & Rundgräber & $2,80 \mathrm{~m} \varnothing$ & - & $\begin{array}{l}\text { "Restos de un } \\
\text { esqueleto" }\end{array}$ & 10 & - & - \\
\hline Sepultura 3 & Rundgräber & $5,50 \mathrm{~m} \varnothing$ & $\begin{array}{c}18 \text { ortostatos }(1,30 \\
\mathrm{m} \text { altura })\end{array}$ & - & 8 & - & - \\
\hline Sepultura 4 & Rundgräber & $3 \mathrm{~m} \varnothing$ & - & "Restos de esqueletos & 5 & - & - \\
\hline Sepultura 5 & Rundgräber & $2 \mathrm{~m} \varnothing$ & - & - & 1 & - & - \\
\hline Sepultura 6 & $\begin{array}{l}\text { Cámara y } \\
\text { corredor }\end{array}$ & $\begin{array}{c}\text { Cámara: } 2,70 \mathrm{x} \\
2,50 \mathrm{~m} \varnothing \\
\text { Corredor: } 1,50 \mathrm{x} \\
0,70 \mathrm{~m} \\
\end{array}$ & 18 ortostatos & "20 esqueletos" & 7 & 7 & 7 \\
\hline Sepultura 7 & $\begin{array}{l}\text { Cámara y } \\
\text { corredor }\end{array}$ & $\begin{array}{c}\text { Cámara: } 2,70 \mathrm{~m} ø \\
\text { Corredor: } 1 \mathrm{~m}\end{array}$ & - & "Restos de esqueletos" & 1 & 1 & 1 \\
\hline Sepultura 8 & Rundgräber & $2,50 \mathrm{~m} \varnothing$ & - & - & 2 & 2 & 1 \\
\hline Sepultura 9 & Rundgräber & $2 \mathrm{mø}$ & - & "Restos de esqueletos" & 3 & 1 & 1 \\
\hline Sepultura 10 & Rundgräber & $1 \mathrm{~m} \varnothing$ & - & - & - & - & - \\
\hline Sepultura 11 & Rundgräber & $2,60 \mathrm{~m} \varnothing$ & - & "Restos de esqueletos" & 2 & - & - \\
\hline Sepultura 12 & Rundgräber & $2 \mathrm{~m} \varnothing$ & - & "Restos de esqueletos" & - & - & - \\
\hline Sepultura 13 & Rundgräber & $2 \mathrm{mø}$ & - & "Restos de esqueletos" & 1 & 1 & 0 \\
\hline Sepultura 14 & Rundgräber & $2 \mathrm{mø}$ & - & "Restos de esqueletos" & 1 & - & - \\
\hline \multicolumn{8}{|c|}{ LLANO DEL JAUTÓN } \\
\hline Sepultura 1 & Rundgräber & $5 \mathrm{~m} \varnothing$ & $\begin{array}{l}28 \text { ortostatos de } \\
\text { pizarra y caliza } \\
(1,30 \mathrm{~m} \text { altura })\end{array}$ & - & 8 & 7 & 7 \\
\hline Sepultura 2 & Rundgräber & $4,50 \mathrm{~m} \varnothing$ & $\begin{array}{c}\text { Mampostería (1,5 m } \\
\text { altura) }\end{array}$ & - & 36 & - & - \\
\hline Sepultura 3 & Rundgräber & $3,5 \mathrm{~m} \varnothing$ & - & - & PR & - & - \\
\hline Sepultura 4 & Rundgräber & $2 \mathrm{~m} \varnothing$ & $\begin{array}{c}\text { Mampostería y } \\
\text { ortostatos }\end{array}$ & - & PR & - & - \\
\hline Sepultura 5 & Rundgräber & $2 \mathrm{~m} \varnothing$ & - & "Restos de esqueletos" & - & & \\
\hline Sepultura $5 b$ & Rundgräber & $6,80 \times 5,60 \mathrm{~m} \varnothing$ & $\begin{array}{c}18 \text { ortostatos y } \\
\text { mampostería }\end{array}$ & $\begin{array}{c}\text { "Restos de } 300 \\
\text { esqueletos " }\end{array}$ & 46 & 2 & 1 \\
\hline Sepultura 6 & $\begin{array}{l}\text { Cámara y } \\
\text { corredor }\end{array}$ & $\begin{array}{c}\text { Cámara: } \\
\text { 3,70 x 3,80 m } \\
\text { Corredor: } \\
2 \times 1 \times 0,6 \mathrm{~m}\end{array}$ & $\begin{array}{c}\text { Cámara: } 11 \\
\text { ortostatos. Corredor: } \\
11 \text { ortostatos y } \\
\text { mampostería }\end{array}$ & "200 esqueletos" & 40 & 2 & 2 \\
\hline
\end{tabular}

Tab. 1. Tipo, características formales e información antropológica de las sepulturas pertenecientes a las necrópolis Las Churuletas, La Atalaya y Llano del Jautón $(\mathrm{PR}=$ pendiente de revisión). $\varnothing$ diámetro. 
las excepcionales dimensiones de su cámara $(6,8$ por $5,6 \mathrm{~m}$ ) y la presencia de un pilar central ${ }^{2}$. La ausencia de corredor en cualquier caso añade incertidumbre a esta propuesta. Además de por sus características arquitectónicas, ambas sepulturas destacan por el elevado número de inhumaciones, según Pedro Flores 300 individuos en la sepultura 5 b y 200 en la tumba 6 , y de elementos de ajuar. Solo en el Jautón 5b se registraron 1.200 objetos (Maicas 2007). Al margen de si tipológicamente estas sepulturas pueden o no ser consideradas como tholoi, parece evidente que son tumbas con un grado de complejidad arquitectónica y funeraria superior al del resto de las tumbas del Grupo Purchena.

En general el ritual funerario practicado en las sepulturas fue fundamentalmente de tipo colecti$\mathrm{vo}^{3}$. Exceptuando las tumbas 5 b y 6 del Llano del Jautón, llegan a documentarse hasta $c a$. 50 individuos (Las Churuletas 3). Los distintos estudios de los restos óseos humanos coinciden en un aspecto de enorme interés: un claro sesgo a favor de fragmentos de cráneo, mandíbula, dientes, metatarsos, metacarpos y falanges de pies y manos (Reverte 1986; Maicas 2005). Esta situación se asemeja a la que se ha documentado recientemente para los restos antropológicos de la necrópolis de Los Millares, perteneciente igualmente a la Colección Siret (Peña Romo 2011).

Diversas hipótesis han tratado de indagar en las posibles causas de esta evidente sobrerrepresentación de determinadas partes anatómicas y de la ausencia de otras. Ruth Maicas (2005) propone que conductas rituales como la impregnación de ciertas unidades anatómicas con materiales como el ocre hayan favorecido la conservación diferencial registrada. Si este fuera el caso, los restos esqueléticos recuperados por Pedro Flores representarían las prácticas funerarias desarrolladas en cada sepultura.

\footnotetext{
${ }^{2}$ Hay cierta confusión en la denominación de las sepulturas 5 y 5 b del Llano del Jautón. Según los cuadernos de excavación de Pedro Flores existen dos sepulturas 5, diferenciadas por su nombre: "Llano del Jautón" y "Loma del Llano del Jautón". Sin embargo, George y Vera Leisner (1943) identificaron erróneamente esta última también como "Llano del Jauntón 5", lo que ha provocado el posterior desconcierto al publicarse dos tumbas 5 con el mismo nombre.

${ }^{3}$ Habitualmente P. Flores en sus diarios de excavación solo indica "restos de cadáver" sin determinar su número.
}

Por su parte, Victoria Peña (2011) plantea una primera hipótesis alternativa de naturaleza conductual. Sugiere que la reorganización de los restos antropológicos en el interior de las sepulturas mediante el fuego habría favorecido la desaparición de algunos huesos, en especial los de tejido esponjoso. Su segunda hipótesis relaciona la ausencia de determinadas partes anatómicas con la propia biografía de la colección antropológica. Siret podría haber repetido lo que hizo con las sepulturas argáricas: separar los cráneos y huesos largos del resto para su estudio antropológico. Ello explicaría la composición actual de la muestra. Sea como fuere, la colección antropológica del "Grupo Purchena", en donde se registran incluso dientes de individuos inmaduros, se caracterizaría por un patrón homogéneo que parece evidenciar una recogida bastante sistemática de los restos óseos contenidos en estos espacios funerarios.

\section{ESTRATEGIA DE MUESTREO: LAS DATACIONES RADIOCARBÓNICAS}

La aproximación a la cronología y temporalidad de las sepulturas megalíticas se ha planificado a partir de dos premisas fundamentales: datar en la medida de lo posible restos óseos humanos y, en estos casos, seleccionar las muestras según el número mínimo de individuos $(\mathrm{NMI})^{4}$. De esta forma, la primera etapa de este trabajo consistió en el análisis de la colección antropológica del "Grupo Purchena" depositada en el Museo Arqueológico Nacional ${ }^{5}$. Las características generales de los restos óseos confirmaban el claro sesgo en favor de restos de cráneo, mandíbula, dientes y en menor medida metatarsos y falanges que son casi los únicos tipos de huesos regis-

\footnotetext{
${ }_{4}^{4}$ En contextos funerarios fundamentalmente con carácter de osario donde los restos antropológicos han perdido sus conexiones anatómicas, la selección de la muestra a partir del NMI es la mejor garantía de evitar datar dos veces al mismo individuo. Esta premisa es básica si se pretende utilizar el modelado bayesiano en la interpretación de las series radiocarbónicas. Téngase en cuenta que el algoritmo usado en este tipo de análisis asume que cada datación es estadísticamente independiente de las otras (Bronk Ramsey 2001).

${ }^{5}$ La caracterización antropológica se debe a Aioze Trujillo Mederos y Jonathan Santana-Cabrera.
} 
trados. Asimismo se confirmaba otro aspecto ya destacado en el estudio de la necrópolis de Las Churuletas (Reverte 1986): los restos antropológicos pertenecen a hombres, mujeres y niños/as sin que, aparentemente, el sexo o las diferencias de edad sean criterios determinantes en las prácticas funerarias.

El estudio antropológico muestra una distribución muy desigual del NMI entre las diferentes sepulturas del "Grupo Purchena" (Tab. 1). Como ya se ha destacado (Maicas 2005; Peña Romo 2011), sorprenden las diferencias entre el NMI documentado y las ocasionales aproximaciones numéricas de Pedro Flores a los individuos registrados en las sepulturas más allá del genérico "restos de cadáver". Por ejemplo, Pedro Flores documenta 50 individuos en la sepultura 3 de las Churuletas frente a los 13 constatados en el estudio antropológico y 200 individuos en la tumba Jautón 6 donde solo se ha identificado un NMI de 40. Parece evidente que la falta de formación de Pedro Flores debió influir en sus estimaciones. No obstante, las diferencias en algunos casos parecen excesivas. Como se indicaba más arriba, la compleja biografía de la Colección Siret ha podido influir de manera decisiva en que algunas sepulturas no conserven el volumen de restos antropológicos inicialmente registrado por Pedro Flores.

Una vez establecido el NMI se seleccionaron las muestras objeto de datación bajo tres condicionantes fundamentales. Primero no todas las tumbas conservan restos antropológicos en los fondos del Museo Arqueológico Nacional (por ejemplo, las tumbas 10 y 12 de la Atalaya y tumba 1 de Las Churuletas). En segundo lugar, el cotejo de los cuadernos de excavación y manuscritos de Pedro Flores y Luis Siret con los materiales del Museo ha permitido identificar mezcla de materiales (sepulturas 5 y 14 de La Atalaya) o informaciones contradictorias en los registros documentales (tumba 3 de esta misma necrópolis) (Maicas 2007). Obviamente, estos casos se han excluido del muestreo. En tercer lugar, no hay información sobre la secuenciación o distribución de los restos antropológicos en el interior de las sepulturas, lo que obliga a considerar cada tumba como un solo conjunto.

Teniendo en cuenta estas limitaciones, la estrategia de datación se ha basado en los siguientes criterios: a) Dado el exiguo NMI identificado en la mayoría de las sepulturas se ha optado por muestrear un número amplio de tumbas que nos aproximara a la temporalidad de los dos tipos fundamentales de sepulturas: rundgräber y tumbas de cámara y corredor. Se han seleccionado muestras de 15 de las 27 sepulturas que componen las tres necrópolis analizadas: 11 rundgräber y 4 tumbas de cámara y corredor (Tab. 1).

b) Se han seleccionado dos sepulturas para establecer su temporalidad a partir de la datación de todas las muestras del NMI identificado: la 6 de la necrópolis de la Atalaya, una tumba de cámara circular y corredor con un NMI de 7 y la sepultura 1 del Llano del Jautón, un rundgräber con un NMI de 8. De la segunda solo se seleccionaron 7 muestras para mantener la integridad de la colección, evitando de esta forma que el muestreo altere su composición.

Del total de 34 muestras seleccionadas se han obtenido 30 dataciones (Tab. 2) ${ }^{6}$. En cuatro casos no fue posible la medición radiométrica por insuficiente colágeno. Todas las dataciones han sido medidas por AMS en tres laboratorios diferentes para valorar si los resultados eran consistentes entre sí, identificando posibles dataciones o conjuntos de fechas con mediciones anómalas. Han sido obtenidas 11 en el Swiss Federal Institute to Technology (ETH) (Zúrich), 10 en el Scottish Universities Environmental Research Centre (SUERC) (East Kilbride, Glasgow) y 9 en el laboratorio Beta Analytic Ltd. (Beta) (Miami) ${ }^{7}$.

\footnotetext{
${ }^{6}$ Todas las dataciones han sido calibradas con la curva IntCal13 mediante el programa OxCal (versión 4.2) (Bronk Ramsey 2009). Siguiendo las recomendaciones de Stuiver y Polach (1977), se han redondeado los resultados a 10 años cuando la desviación típica era igual o superior a 25 años y a 5 años si era inferior.

${ }^{7}$ Los procedimientos seguidos por el ETH se describen en Bonani et al. (1987), Synal et al. (1997; Synal et al. 2007) y Hajdas (2008), los del SUERC en Dunbar et al. (2016) y los de Beta en http://www.radiocarbon.com/ (10 de enero de 2016).
} 


\begin{tabular}{|c|c|c|c|c|c|c|c|}
\hline Tumba & Tipo & $\begin{array}{c}\text { Código } \\
\text { Laboratorio }\end{array}$ & $\begin{array}{c}\delta^{13} \mathrm{C} \\
\text { (AMS) } \\
\% 0\end{array}$ & $\begin{array}{c}\delta^{13} \mathrm{C} \\
(\mathrm{IRMS}) \\
\%\end{array}$ & Edad BP & $\begin{array}{c}\text { Datación calibrada } \\
(68 \% \text { probabilidad) } \\
\text { Cal BC }\end{array}$ & $\begin{array}{c}\text { Datación calibrada } \\
\text { (95\% probabilidad) } \\
\text { Cal BC }\end{array}$ \\
\hline \multicolumn{8}{|c|}{ NECRÓPOLIS DE LAS CHURULETAS } \\
\hline Tumba 1 & Rundgräber & Beta-439073 & - & $-20,0$ & $4200 \pm 30$ & $2890-2700$ & $2900-2670$ \\
\hline Tumba 2 & Rundgräber & Beta-421155 & - & $-19,2$ & $4680 \pm 30$ & $3520-3370$ & $3630-3360$ \\
\hline \multirow{3}{*}{ Tumba 3} & \multirow{3}{*}{ Rundgräber } & Beta-439075 & - & $-18,8$ & $4790 \pm 30$ & $3640-3530$ & $3650-3520$ \\
\hline & & Beta-421156 & - & $-19,1$ & $4490 \pm 30$ & $3340-3100$ & $3350-3090$ \\
\hline & & Beta-439074 & - & $-19,4$ & $4200 \pm 30$ & $2890-2700$ & $2900-2670$ \\
\hline \multirow{2}{*}{ Tumba 4} & \multirow{2}{*}{$\begin{array}{l}\text { Cámara y } \\
\text { corredor }\end{array}$} & Beta-421157 & - & $-19,5$ & $4470 \pm 30$ & $3330-3090$ & $3340-3020$ \\
\hline & & Beta-439076 & - & $-19,0$ & $3980 \pm 30$ & $2570-2460$ & $2580-2450$ \\
\hline Tumba 5 & Rundgräber & Beta-421158 & - & $-19,5$ & $4530 \pm 30$ & $3360-3110$ & $3370-3100$ \\
\hline Tumba 6 & Rundgräber & Beta-439078 & - & $-19,1$ & $4180 \pm 30$ & $2880-2690$ & $2890-2660$ \\
\hline \multicolumn{8}{|c|}{ NECRÓPOLIS DE LA ATALAYA } \\
\hline Tumba 1 & Rundgräber & SUERC-69010 & - & $-19,7$ & $4050 \pm 29$ & $2620-2490$ & $2840-2480$ \\
\hline \multirow{7}{*}{ Tumba 6} & \multirow{7}{*}{$\begin{array}{l}\text { Cámara y } \\
\text { corredor }\end{array}$} & SUERC-69013 & - & $-19,2$ & $4041 \pm 29$ & $2620-2490$ & $2840-2470$ \\
\hline & & SUERC-69012 & - & $-19,0$ & $4012 \pm 29$ & $2570-2480$ & $2620-2460$ \\
\hline & & SUERC-69011 & - & $-19,4$ & $3959 \pm 25$ & $2570-2460$ & $2570-2340$ \\
\hline & & ETH-74311 & $-15,3$ & - & $3928 \pm 20$ & $2475-2345$ & $2480-2340$ \\
\hline & & ЕTH-74310 & $-16,6$ & - & $3925 \pm 20$ & $2475-2345$ & $2480-2340$ \\
\hline & & ETH-74309 & $-16,4$ & - & $3922 \pm 20$ & $2470-2345$ & $2475-2340$ \\
\hline & & ЕTH-74308 & $-24,1$ & - & $3844 \pm 20$ & $2345-2210$ & $2455-2200$ \\
\hline Tumba 7 & $\begin{array}{l}\text { Cámara y } \\
\text { corredor }\end{array}$ & SUERC-69017 & - & $-19,6$ & $4883 \pm 29$ & $3700-3640$ & $3710-3630$ \\
\hline Tumba 8 & Rundgräber & SUERC-69018 & - & $-17,6$ & $4582 \pm 29$ & $3490-3190$ & $3500-3110$ \\
\hline Tumba 9 & Rundgräber & SUERC-69019 & - & $-19,3$ & $4578 \pm 29$ & $3490-3140$ & $3500-3110$ \\
\hline \multicolumn{8}{|c|}{ NECRÓPOLIS DEL LLANO DEL JAUTÓN } \\
\hline \multirow{7}{*}{ Tumba 1} & \multirow{7}{*}{ Rundgräber } & ETH-74314 & $-18,5$ & - & $4175 \pm 20$ & $2875-2700$ & $2880-2675$ \\
\hline & & ETH-74313 & $-17,4$ & - & $4164 \pm 20$ & $2875-2695$ & $2880-2665$ \\
\hline & & ETH-74312 & $-18,3$ & - & $4163 \pm 20$ & $2875-2695$ & $2880-2665$ \\
\hline & & ETH-74318 & $-17,3$ & - & $4153 \pm 20$ & $2870-2675$ & $2875-2635$ \\
\hline & & ETH-74317 & $-16,6$ & - & $4151 \pm 20$ & $2865-2670$ & $2875-2635$ \\
\hline & & ETH-74315 & $-13,2$ & - & $4148 \pm 20$ & $2865-2670$ & $2875-2630$ \\
\hline & & ETH-74316 & $-19,3$ & - & $4112 \pm 20$ & $2850-2615$ & $2860-2575$ \\
\hline \multirow{2}{*}{ Tumba $5 b$} & \multirow{2}{*}{ Rundgräber } & SUERC-69020 & - & $-18,6$ & $4219 \pm 29$ & $2900-2760$ & $2910-2690$ \\
\hline & & - & $-19,6$ & - & $4160 \pm 60$ & $2880-2660$ & $2890-2580$ \\
\hline \multirow{2}{*}{ Tumba 6} & \multirow{2}{*}{$\begin{array}{l}\text { Cámara y } \\
\text { corredor }\end{array}$} & SUERC-69021 & - & $-19,0$ & $4264 \pm 29$ & $2910-2880$ & $2930-2770$ \\
\hline & & SUERC-69022 & - & $-18,8$ & $4189 \pm 24$ & $2880-2705$ & $2890-2675$ \\
\hline
\end{tabular}

Tab. 2. Dataciones radiocarbónicas de las necrópolis de Las Churuletas, La Atalaya y Llano del Jautón. 


\section{CRONOLOGÍA Y TEMPORALIDAD DEL "GRUPO PURCHENA"}

La serie radiocarbónica de las tres necrópolis analizadas suma 31 dataciones (Tabs. 1 y 2): 30 que se presentan en este trabajo y una publicada por Ruth Maicas (2007) perteneciente a la tumba 5 b del Llano del Jautón (4160 \pm 60 BP, 2880-2660 cal BC a $1 \sigma$ y $2890-2580$ cal BC a $2 \sigma$ ). Por primera vez en el estudio de las tradicionalmente consideradas primeras manifestaciones megalíticas del sureste peninsular se ha obtenido una serie radiométrica que permite una aproximación a su temporalidad. Para su interpretación se ha utilizado la estadística Bayesiana que, además de reducir los intervalos de probabilidad combinando las dataciones radiocarbónicas con otro tipo de información cronológica, crea estimaciones probabilísticas para el comienzo y final de las fases donde las dataciones son agrupadas y cuantifica en años calendáricos su duración (Bronk Ramsey 1995; Bayliss et al. 2007).

Junto a la modelización Bayesiana se ha recurrido a la suma de probabilidades, una herramienta estadística ampliamente utilizada en la literatura arqueológica para medir la duración e intensidad de los fenómenos analizados (Ottaway 1973; Aitchison et al. 1991). No obstante, esta técnica presenta varias limitaciones que deben considerarse al valorar los resultados. El método no contrarresta la dispersión estadística intrínseca a las dataciones radiocarbónicas, lo que provoca que la duración de los fenómenos dependa del número de dataciones y de su desviación típica (Bayliss et al. 2007). Además, la forma específica que la curva de calibración adquiere en cada tramo influye en la mayor o menor extensión del intervalo temporal calculado y potencialmente en la presencia de teóricos hiatus temporales (Michczyński y Michczyńska 2006).

Teniendo en cuenta todos estos condicionantes, la serie radiocarbónica ha sido analizada modelando las dataciones a partir de diferentes criterios culturales. El primero ha sido el tipo de sepultura. De esta forma, las dataciones se han agrupado en dos conjuntos dependiendo de si pertenecen a rundgräber $(\mathrm{n}=19)$ o a sepulturas de cámara circular y corredor $(\mathrm{n}=12)$. El modelado bayesiano de cada conjunto asume que las dataciones de cada fase se corresponden con un periodo de actividad continuada, mostrando un índice de co-

\begin{tabular}{|c|c|c|c|}
\hline Fase/Evento & Parámetro & $\begin{array}{c}\text { Dataciones modeladas } \\
\text { (68\% de } \\
\text { probabilidad cal BC) }\end{array}$ & $\begin{array}{c}\text { Dataciones modeladas } \\
(95 \% \text { de } \\
\text { probabilidad cal BC) }\end{array}$ \\
\hline \multicolumn{4}{|c|}{ Modelos por tipos de sepultura (Fig. 2) } \\
\hline \multirow{3}{*}{ Rundgräber } & Inicio & $3665-3530$ & $3730-3390$ \\
\hline & Final & $2650-2505$ & $2705-2405$ \\
\hline & Duración & 850-1005 años & 730-1065 años \\
\hline \multirow{3}{*}{$\begin{array}{l}\text { Cámara y } \\
\text { corredor }\end{array}$} & Inicio & $3805-3650$ & $4100-3635$ \\
\hline & Final & $2355-2155$ & $2415-1920$ \\
\hline & Duración & 1280-1390 años & 1230-1465 años \\
\hline \multicolumn{4}{|c|}{ Modelos por necrópolis (Fig. 3) } \\
\hline \multirow{3}{*}{$\begin{array}{l}\text { Las } \\
\text { Churuletas }\end{array}$} & Inicio & $3730-3540$ & $\begin{array}{c}4020-3515(93.1 \%) \\
3500-3410(2.3 \%)\end{array}$ \\
\hline & Final & $2555-2370$ & $2575-2080$ \\
\hline & Duración & 980-1085 años & 935-1170 años \\
\hline \multirow{3}{*}{ La Atalaya } & Inicio & $3820-3650$ & $4125-3635$ \\
\hline & Final & $2355-2145$ & $2415-1870$ \\
\hline & Duración & 1280-1400 años & 1235-1465 años \\
\hline \multirow{3}{*}{$\begin{array}{l}\text { Llano del } \\
\text { Jautón }\end{array}$} & Inicio & $2925-2775$ & $\begin{array}{r}2965-2755(92.8 \%) \\
2730-2710(2.6 \%) \\
\end{array}$ \\
\hline & Final & $2775-2655$ & $\begin{array}{r}2810-2600(88.8 \%) \\
2865-2825(6.6 \%) \\
\end{array}$ \\
\hline & Duración & 5-195 años & $0-235$ años \\
\hline \multicolumn{4}{|c|}{ Modelos de las sepulturas con NMI datados (Fig. 4) } \\
\hline \multirow{3}{*}{ Jautón 1} & Inicio & $2880-2715$ & $2910-2690$ \\
\hline & Final & $2750-2650$ & $\begin{array}{c}2815-2585(91.1 \%) \\
2860-2830(4.2 \%) \\
\end{array}$ \\
\hline & Duración & 0-90 años & 0-175 años \\
\hline \multirow{3}{*}{ La Atalaya 6} & Inicio & $2570-2485$ & $2655-2470$ \\
\hline & Final & $2460-2340$ & $2465-2225$ \\
\hline & Duración & 30-170 años & $15-260$ años \\
\hline \multicolumn{4}{|c|}{ Modelo de los contextos funerarios (Fig. 5) } \\
\hline \multirow{3}{*}{$\begin{array}{l}\text { Prácticas } \\
\text { funerarias pre- } \\
\text { megalíticas }\end{array}$} & Inicio & $4975-4785$ & $5060-4730$ \\
\hline & Final & $4740-4570$ & $4790-4430$ \\
\hline & Duración & $55-265$ años & 0-350 años \\
\hline \multirow{3}{*}{$\begin{array}{l}\text { Prácticas } \\
\text { funerarias } \\
\text { megalíticas }\end{array}$} & Inicio & $3730-3650$ & $3845-3550$ \\
\hline & Final & $2395-2270$ & $2435-2190$ \\
\hline & Duración & 1245-1355 años & 1190-1420 años \\
\hline \multicolumn{4}{|c|}{ Modelo de los asentamientos (Fig. 7) } \\
\hline \multirow{3}{*}{ Neolitico } & Inicio & $5345-4900$ & $6080-4745$ \\
\hline & Final & $4910-4440$ & $5035-3610$ \\
\hline & Duración & $135-280$ años & 60-355 años \\
\hline \multirow{3}{*}{ Calcolítico } & Inicio & $2925-2780$ & 2970-2755 \\
\hline & Final & $2295-2205$ & $2335-2160$ \\
\hline & Duración & 485-635 años & 440-705 años \\
\hline
\end{tabular}

Tab. 3. Estimaciones probabilísticas de los diferentes modelados bayesianos. NMI Número Mínimo de Individuos. 


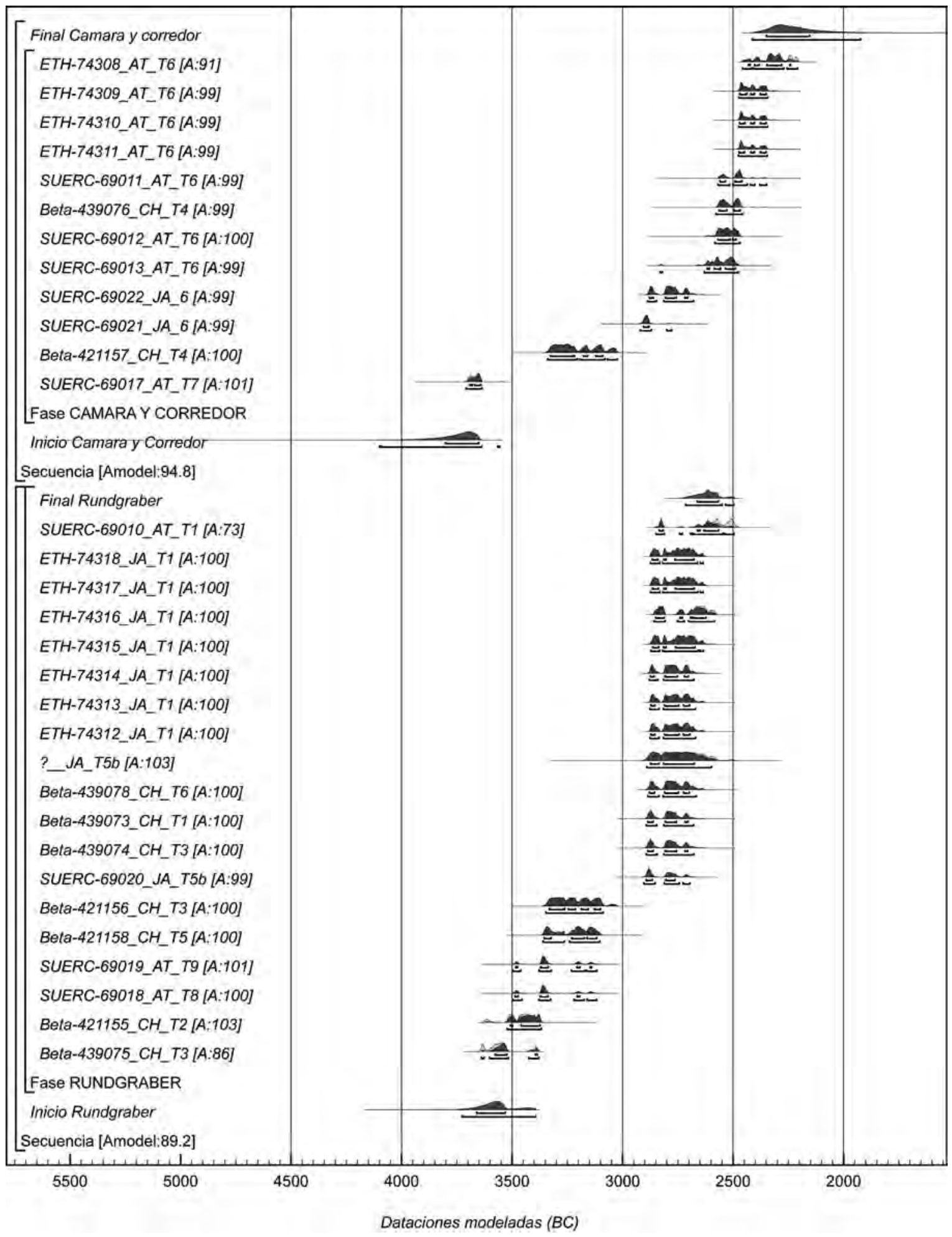

Fig. 2. Modelados bayesianos de las dataciones agrupadas por tipo de sepultura: rundgräber (Las Churuletas 1 a 3, 5 y 6; La Atalaya 1, 8 y 9; Llano del Jautón 1 y 5 b) y de cámara y corredor (Las Churuletas 4; La Atalaya 6 y 7; Llano del Jautón 6) del "Grupo Purchena" (Almería) (véanse tablas 1 a 3).

Trab. Prehist., 74, N. ${ }^{\circ} 2$, julio-diciembre 2017, pp. 257-277, ISSN: 0082-5638 doi: $10.3989 /$ tp.2017.12194 
rrelación elevado $\left(\mathrm{A}_{\text {model }}=89,2 \%\right.$ y $\mathrm{A}_{\text {model }}=94,8 \%$ respectivamente) ${ }^{8}$ (Fig. 2). El inicio de la actividad funeraria se produciría en el caso de los rundgräber entre el 3665-3530 cal BC (68\% de probabilidad $)^{9}$ y para las sepulturas de cámara circular y corredor entre el 3805-3650 cal BC (68\% de probabilidad) (Tab. 3). La primera mitad de IV milenio parece, por tanto, la fecha más probable para el inicio del fenómeno megalítico en el sureste peninsular.

La actividad funeraria durante el IV milenio parece que fue poca intensa si tenemos en cuenta las escasas dataciones existentes para estos momentos. No va a ser hasta época calcolítica cuando el uso de ambos tipos de sepultura adquiera su máximo desarrollo aunque con una importante diferencia. Las dataciones de los rundgräber se concentran en la primera mitad del III milenio cal $\mathrm{BC}$, frente a las tumbas de cámara y corredor que lo hacen, sobre todo, a partir de mediados del III milenio cal BC, cuando la actividad en los primeros casi había finalizado (véase discusión más abajo).

La estimación probabilística para el final de las prácticas funerarias marca otra diferencia relevante. En los rundgräber se produciría entre el 2650-2505 cal BC (68\% de probabilidad) y en las tumbas de cámara y corredor entre el 23552155 cal BC (68\% de probabilidad). La actividad funeraria habría finalizado antes de la aparición de las primeras manifestaciones culturales características de la Edad del Bronce, lo que contrasta con las sepulturas tipo tholos, una de cuyas principales características es la continuidad ritual, sobre todo en época argárica (Aranda Jiménez y Lozano Medina 2014; Lozano Medina y Aranda Jiménez 2017; Aranda Jiménez et al. 2017a). En años calendáricos, el periodo de uso de los rundgräber es más corto, entre 850-1005 años (68\% de probabilidad), frente a las tumbas de cámara circular y corredor, entre 1280-1390 años (68\% de probabilidad).

\footnotetext{
${ }^{8}$ La modelización bayesiana incorpora un estadístico denominado índice de correlación (index of agreement) que por debajo del $60 \%$ supone que el modelo posee una baja coherencia interna y debe ser revisado (Bronk Ramsey 1995: 427-8).

9 Todas las estimaciones de los momentos de inicio, final y duración de las fases que se citan en el texto han sido establecidas a partir de las funciones Boundary Start, Boundary End y Span por el programa Oxcal (v.4.2).
}

En un segundo nivel de análisis, las dataciones se han agrupado por necrópolis: Las Churuletas $(n=9)$, La Atalaya $(n=11)$ y Llano del Jautón $(\mathrm{n}=11)$. En las tres se han datado sepulturas rundgräber y de cámara y corredor. El modelado bayesiano ${ }^{10}$ muestra para las necrópolis de Las Churuletas y La Atalaya dos series parecidas en su temporalidad (Fig. 3), siendo su principal diferencia la estimación para el final de la actividad funeraria, entre el 2555-2370 cal BC (68\% de probabilidad) en Las Churuletas frente al 2355-2145 (68\% de probabilidad) cal BC en La Atalaya. La distribución interna de las dataciones también enfrenta a ambas necrópolis. En Las Churuletas la distribución es sostenida a lo largo del periodo de uso en contraposición a la concentración de dataciones a mediados y primeros siglos de las segunda mitad del III milenio cal BC en la necrópolis de La Atalaya. En años calendáricos el periodo de uso es superior en La Atalaya, entre 1280-1400 años (68\% de probabilidad), frente a los $980-1085$ años (68\% de probabilidad) de Las Churuletas.

No obstante, Llano del Jautón es la necrópolis mas diferenciada. La serie radiocarbónica disponible muestra un corto periodo de uso que se iniciaría entre el $2925-2775$ cal BC (68\% de probabilidad) y finalizaría entre el 2775-2655 cal BC (68\% de probabilidad). Esto en años calendáricos supone un intervalo entre 5-195 años (68\% de probabilidad). Es decir, la necrópolis concentra su actividad funeraria exclusivamente en los primeros siglos del III milenio cal BC, en pleno periodo calcolítico. Así, la temporalidad de la necrópolis de Llano del Jautón difiere substancialmente de la mostrada por Las Churuletas y La Atalaya. Esto implicaría que al interior del denominado "Grupo Purchena" hay importantes diferencias cronológicas de unas necrópolis a otras.

El tercer nivel de análisis ha consistido en el modelado estadístico de las dos series radiocarbónicas obtenidas para las sepulturas Atalaya 6 y Llano del Jautón 1 ( $\mathrm{A}_{\text {model }}=84,1 \%$ y $\mathrm{A}_{\text {model }}=98,7 \%$ respectivamente). Como ya se ha indicado, el objetivo ha sido aproximarnos a la temporalidad de su uso funerario a partir de la datación del NMI identificado en cada una (Fig. 4). De esta forma, la serie radiocarbónica de la tumba tipo rundgräber del Llano del Jautón 1, se caracteriza por su

\footnotetext{
${ }^{10}$ El índice de correlación es elevado en las tres necrópolis (véase Fig. 3).
} 


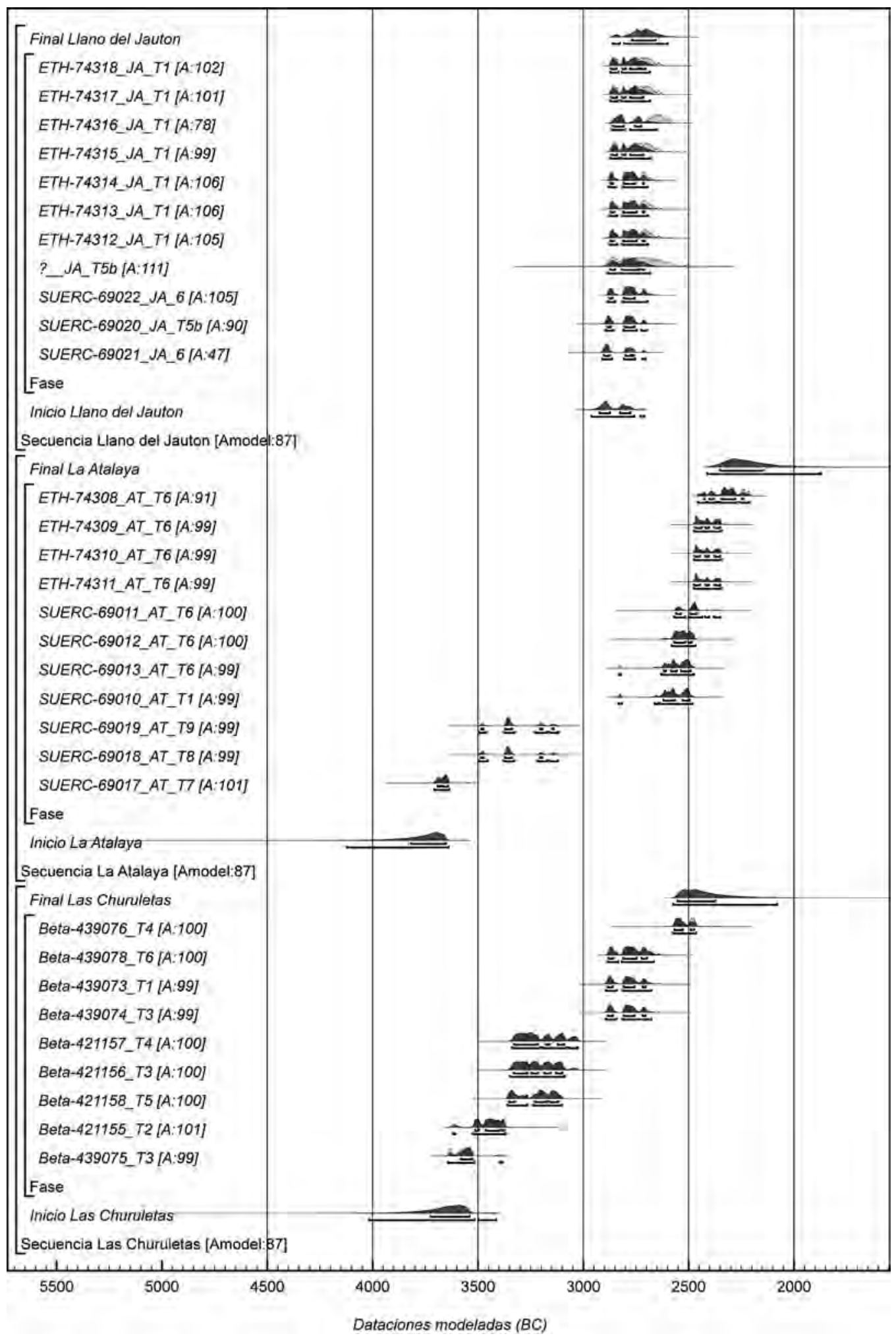

Fig. 3. Modelados bayesianos de las dataciones agrupadas por necrópolis: Las Churuletas, La Atalaya y Llanos del Jautón del "Grupo Purchena" (Almería) (véanse tablas 1 a 3).

Trab. Prehist., 74, N. ${ }^{\circ}$ 2, julio-diciembre 2017, pp. 257-277, ISSN: 0082-5638 doi: $10.3989 /$ tp.2017.12194 
coherencia interna ya que todas las dataciones comparten un intervalo cronológico muy similar. El inicio de la actividad funeraria se produciría entre el $2880-2715$ cal BC (68\% de probabilidad) y el final entre el 2750-2650 cal BC (68\% de probabilidad), lo que en años calendáricos supone entre 0-90 años (68\% de probabilidad). El test de contemporaneidad muestra igualmente la consistencia interna de las dataciones incluidas en el modelo $\left(T^{\prime}=6,0 ; T^{\prime}(5 \%)=12,6\right)($ Ward y Wilson 1978). Esto sugiere que todos los individuos fallecieron en un reducido intervalo temporal, entre una y cuatro generaciones si asumimos una media de 25 años por generación, o incluso al mismo tiempo. Si este fuera el caso, el intervalo temporal más probable en el que podrían haber sido depositados los restos antropológicos sería entre 2818-2665 cal BC (86,7\% de probabilidad; sum).

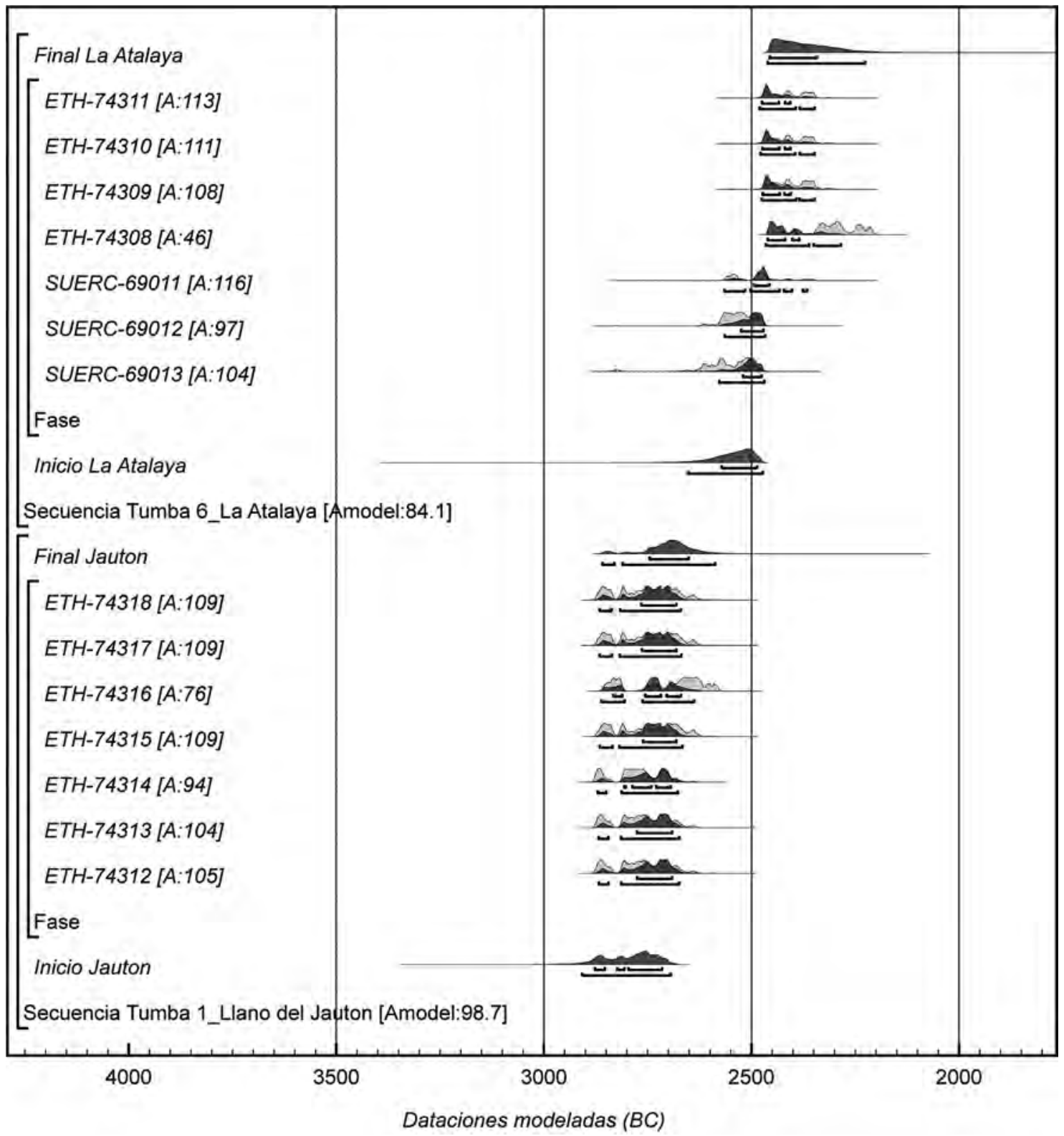

Fig. 4. Modelados bayesianos de las sepulturas La Atalaya 6 (cámara y corredor) y Llano del Jautón 1 (rundgräber) del "Grupo Purchena" (Almería) (véanse tablas 1 a 3). 
En el modelado de la serie radiocarbónica de La Atalaya $6\left(\mathrm{~A}_{\text {model }}=87 \%\right)$, una sepultura de cámara circular y corredor, el inicio de la actividad funeraria ocurriría entre el 25702485 cal BC (68\% de probabilidad), cuando las prácticas funerarias en el Llano del Jautón 1 ya habrían finalizado. Los últimos enterramientos se producirían entre el 2460-2340 cal BC (68\% de probabilidad). Esto evidencia un periodo de uso igualmente breve, aunque en este caso las dataciones no forman un grupo estadísticamente consistente $\left(T^{\prime}=42,7 ; T^{\prime}(5 \%)=12,6\right)$ (Ward y Wilson 1978). En años calendáricos supone un periodo entre 30-170 años (68\% de probabilidad), lo que implicaría entre dos y siete generaciones. Aunque en momentos cronológicos diferentes, ambas tumbas comparten una temporalidad parecida. Muestran un periodo de uso relativamente breve que contrasta con la actividad prolongada que evidencian las tres dataciones de, por ejemplo, la tumba 3 de Las Churuletas (véase Tab. 2). Parece, por tanto, que existe una cierta heterogeneidad en la mayor o menor perduración temporal de las diferentes sepulturas que forman las necrópolis analizadas.

\section{LA TEMPORALIDAD DEL "GRUPO PURCHENA" EN EL CONTEXTO DEL NEOLÍTICO Y EDAD DEL COBRE DE LA CUENCA DEL ALMANZORA Y DEPRESIÓN DE VERA}

La serie radiocarbónica discutida en este trabajo permite el análisis de la temporalidad de las primeras manifestaciones megalíticas del sureste de la Península Ibérica, así como de su integración en la secuencia cronológica general del Neolítico y Edad del Cobre. Para ello, se ha seleccionado como ámbito geográfico de referencia la cuenca del alto Almanzora, donde se sitúa Purchena, y la depresión de Vera formada por el bajo Almanzora y las cuencas de los ríos Aguas y Antas. Esta amplia comarca es clave para el estudio de los cambios e innovaciones culturales que desencadenaron un proceso de creciente complejidad social sin parangón en el resto de la Península Ibérica y que ha generado un enorme interés científico y una intensa actividad arqueológica (Aranda Jiménez et al. 2015).
Hemos seleccionado en ese ámbito todas las dataciones de contextos funerarios y de asentamientos de época neolítica y de la Edad del Cobre cuya desviación estándar fuera inferior a 100 años. Se pretende reducir así el efecto negativo que las amplias desviaciones tienen en las estimaciones probabilísticas. Tampoco se han tenido en cuenta las dataciones contradictorias con el contexto cultural datado ${ }^{11} \mathrm{o}$ las realizadas combinando materiales que podrían pertenecer a diferentes organismos ${ }^{12}$. Las fechas consideradas para los contextos funerarios, además de las incluidas en este trabajo, proceden de Cerro Virtud (Montero et al. 1999; Ruiz-Taboada y Montero 1999). En el caso de los asentamientos, se han tenido en cuenta las dataciones de Cabecicos Negros ${ }^{13}$ (Camalich Massieu y Martín Socas 2013), Las Pilas (Murillo Barroso et al. 2017), Almizaraque (Almagro Gorbea 1972; Alonso et al. 1978; Castaño et al. 1991) y Campos (Mederos 1995). Suman 38 dataciones de cada serie que pueden consultarse en la base de datos de acceso libre CronoloGEA (http://www.webgea.es/dataciones/ [último acceso 10/01/2017].

El total de 76 fechas es un número exiguo que obviamente limita el alcance de las valoraciones que puedan realizarse. Ambas series se han analizado mediante la suma de probabilidades y modelización bayesiana. Se ha establecido una secuencia en dos fases para las dataciones funerarias: una pre-megalítica agrupa las dataciones del enterramiento colectivo en fosa de Cerro Virtud, y otra megalítica incluye las dataciones presentadas en este trabajo (Fig. 5) $\left(\mathrm{A}_{\text {model }}\right.$ $=91 \%$ ). Las primeras manifestaciones funerarias datadas se sitúan en la primera mitad del V milenio con una estimación probabilística para su inicio de entre el 4975-4785 cal BC $(68 \%$ de probabilidad) y entre el $4740-4570$ cal BC (68\%

${ }^{11}$ La falta en numerosos yacimientos de una discusión sobre las dataciones y sus contextos de procedencia provoca un alto grado de incertidumbre cuando aquellas se alejan de su contexto cultural general. Hemos preferido excluirlas mientras no se aclaren estas discrepancias.

12 Por ejemplo las dataciones de Cerro Virtud, Beta-101424 y Beta-110875, que combinan varios fragmentos de carbón vegetal (Ruiz-Taboada y Montero 1999).

${ }_{13}$ Son dataciones sobre concha, calibradas con la curva Marine13. Dada la ausencia de valores Delta $\mathrm{R}$ específicos de esta zona, la variabilidad regional se ha corregido mediante el parámetro $\Delta \mathrm{R}=58 \pm 85$ años que Reimer y McCormac (2002) consideran representativo del Mediterráneo. 
de probabilidad) para el final. Tras este episodio funerario parece existir un hiatus, posiblemente más teórico que real (Fig. 6). La ausencia de programas de dataciones de contextos funerarios habituales en época neolítica, como por ejemplo las cuevas, es evidente que impide una visión mucho más aproximada a la temporalidad de este fenómeno.

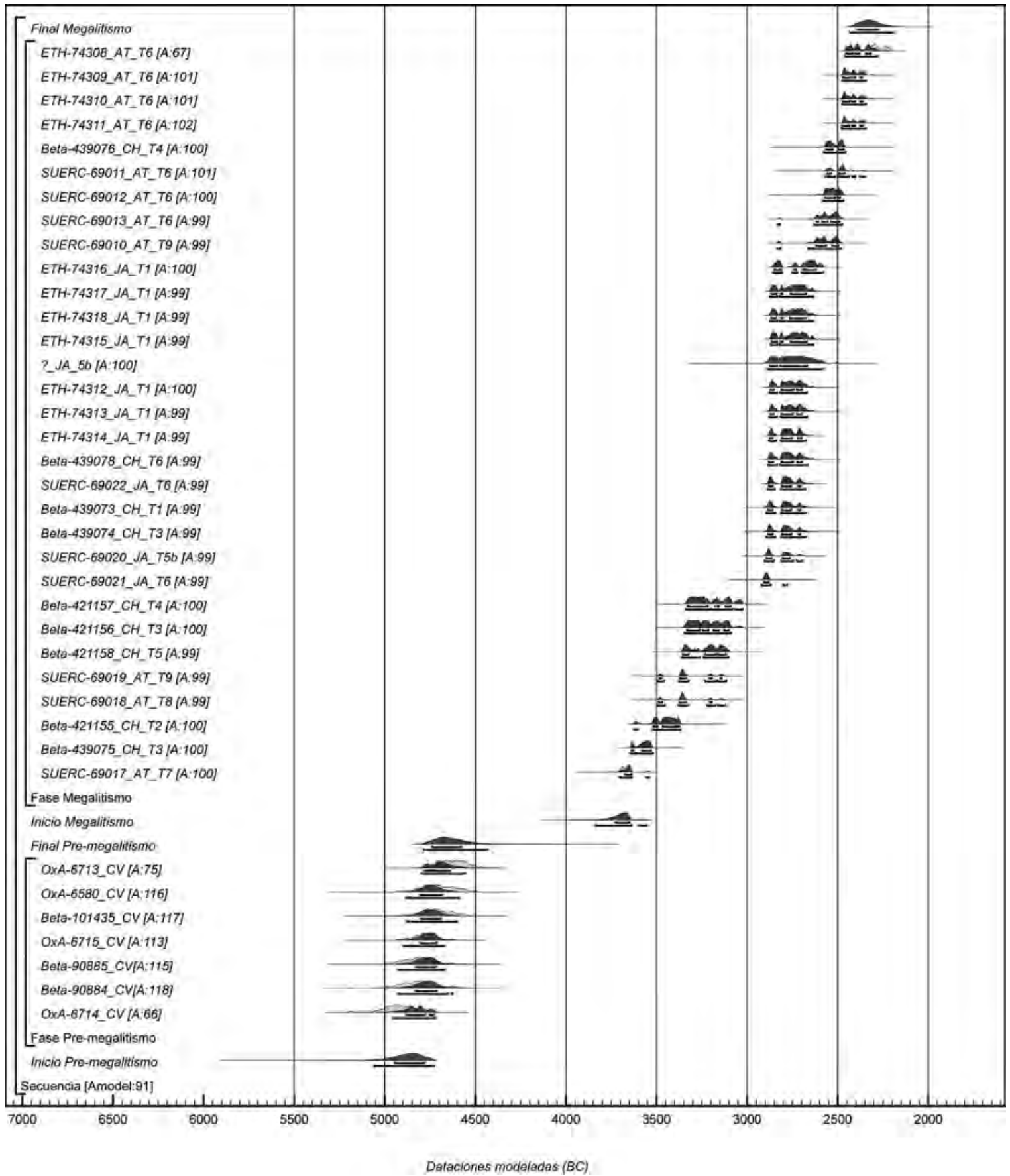

Fig. 5. Modelado bayesiano de la serie radiocarbónica funeraria neolítica y calcolítica de la cuenca alta del Almanzora y Depresión de Vera (véase tabla 3). 


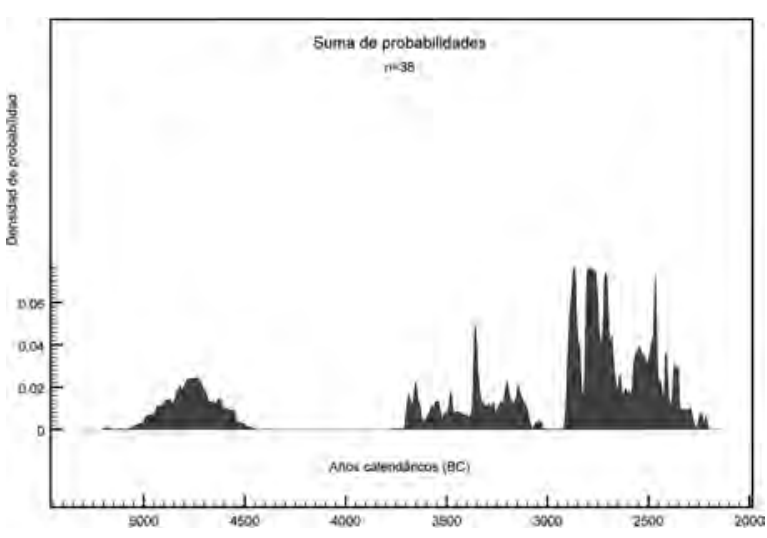

Fig. 6. Suma de probabilidades de la serie radiocarbónica funeraria modelada en la figura 5.
Sea como fuere, las sepulturas megalíticas constituyen la principal práctica funeraria del periodo. Su inicio se produciría entre el 3845-3550 cal BC (95\% de probabilidad), posiblemente entre el 3730-3650 cal BC si consideramos el intervalo a un $68 \%$ de probabilidad. No obstante y como ya se ha destacado, la actividad funeraria durante el IV milenio parece que fue de poca intensidad dadas las pocas dataciones existentes. El cambio de milenio sería el punto de inflexión en esta dinámica. A partir de entonces, ya en época calcolítica, aumentarían de modo significativo las prácticas funerarias, en especial en la primera mitad del III milenio cal BC. El final de la serie radiocarbónica funeraria ocurría entre el 2435-2190 cal BC (95\%

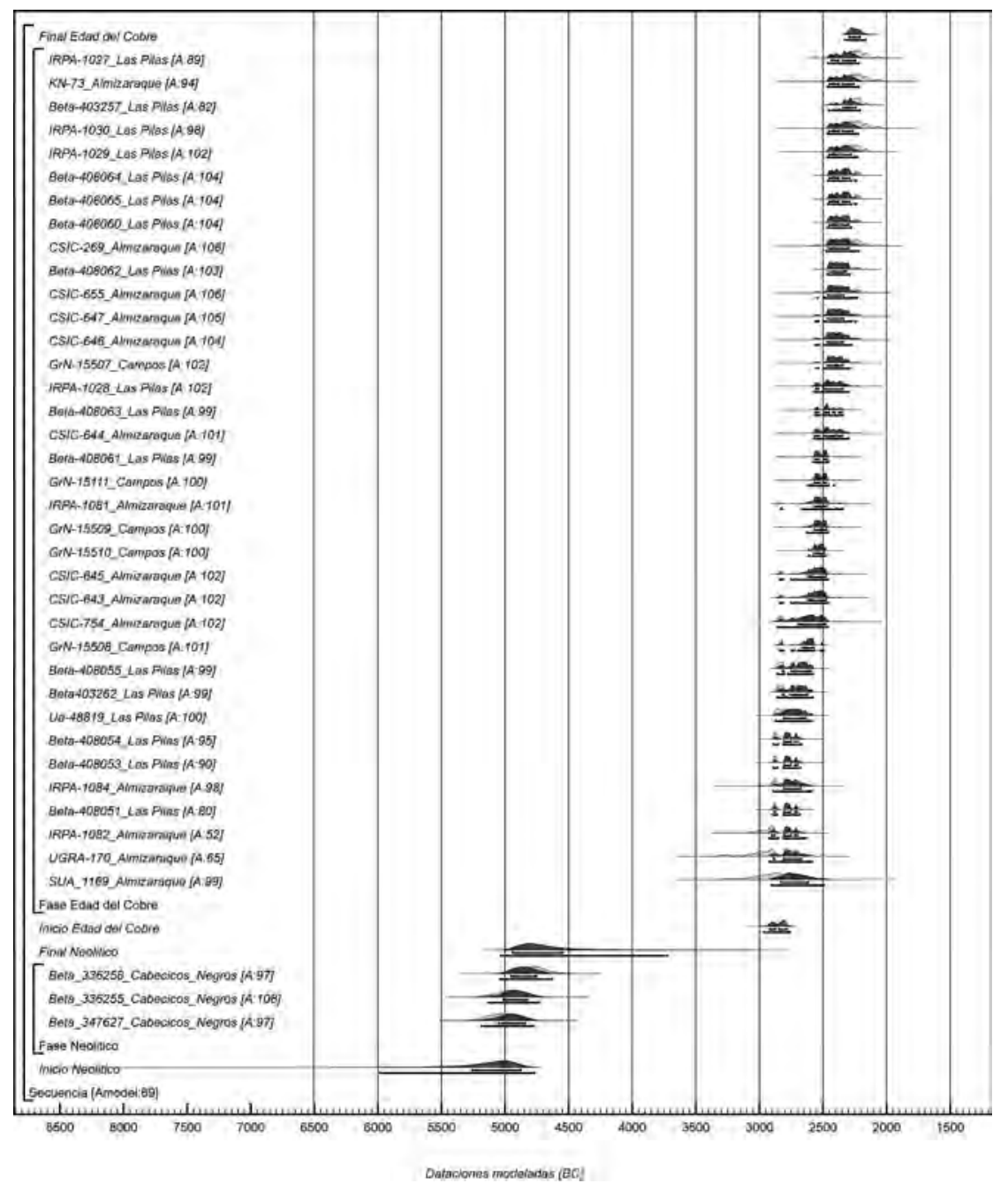

Fig. 7. Modelado bayesiano de la serie radiocarbónica de los asentamientos neolíticos y calcolíticos de la cuenca alta del Almanzora y Depresión de Vera (véase tabla 3).

Trab. Prehist., 74, N. ${ }^{\circ}$ 2, julio-diciembre 2017, pp. 257-277, ISSN: 0082-5638

doi: $10.3989 /$ tp.2017.12194 
de probabilidad), posiblemente entre el 2395-2270 cal BC (68\% de probabilidad).

Destacamos diferentes aspectos de la comparación entre las series radiocarbónicas domésticas y funerarias de época neolítica y calcolítica (Figs. 7 y 8). El primero es la falta de dataciones radiocarbónicas de asentamientos para época neolítica si se exceptúan las procedentes de Cabecicos Negros que se sitúan a finales del VI milenio y, sobre todo, en la primera mitad del V milenio cal BC (Camalich Massieu y Martín Socas 2013). Obviamente este hecho contrasta con el poblamiento neolítico bien conocido en toda la comarca sobre todo a partir de prospecciones (Castro et al. 1998; Delibes et al. 1996; Camalich Massieu y Martín Socas 1999; Román et al. 1996; Román et al. 2000). Esta ausencia de mediciones radiocarbónicas en buena parte del Neolítico también contrasta con la serie funeraria en especial megalítica cuya larga duración, como se ha analizado, se inicia en la primera mitad del IV milenio.

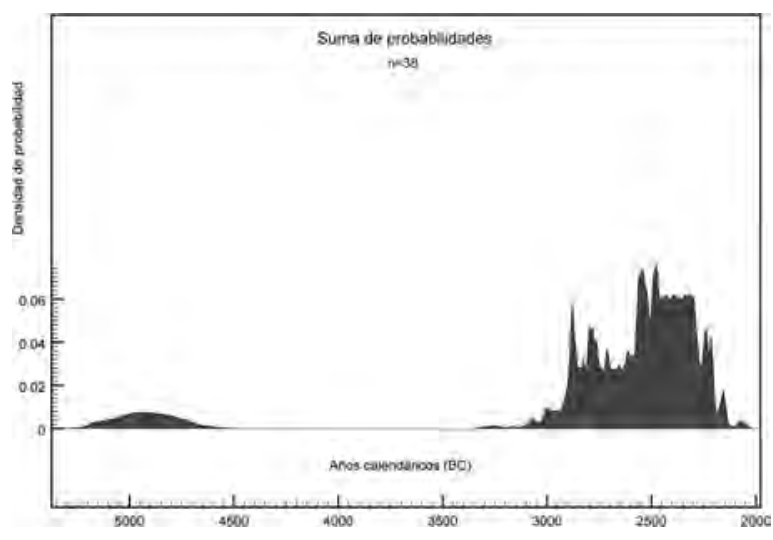

Fig. 8. Suma de probabilidades de la serie radiocarbónica funeraria modelada en la figura 7.

En segundo lugar, es durante la Edad del Cobre cuando realmente sucederían importantes cambios en las características del poblamiento que explicarían la importante concentración de dataciones en este periodo (véase discusión más adelante). De acuerdo con el modelado bayesiano $\left(\mathrm{A}_{\text {model }}\right.$ $=89 \%$ ) (Fig. 7), la Edad del Cobre se iniciaría entre el 2970-2755 cal BC (95\% de probabilidad), posiblemente entre el $2925-2780$ cal BC $(68 \%$ de probabilidad). El final de los poblados calcolíticos ocurriría entre el 2335-2160 cal BC (95\% de probabilidad) o si tenemos en cuenta la estimación al $68 \%$ de probabilidad entre el 2295-2205 cal BC. Este periodo de intensa actividad en el poblamiento de la comarca es plenamente coincidente con el incremento en las prácticas funerarias megalíticas que se producirían a partir del $3000 \mathrm{cal}$ BC. La temporalidad del máximo desarrollo en el uso tanto de sepulturas tipo rundgräber como de cámara y corredor, es la misma que la de la ocupación de los poblados calcolíticos. Parece por tanto razonable suponer que existió una estrecha relación entre ambos fenómenos.

\section{CONCLUSIONES}

Por primera vez desde el inicio de las investigaciones sobre el megalitismo en el sureste de la Península Ibérica, gracias al programa de dataciones radiocarbónicas que desde 2012 venimos desarrollando, disponemos de un criterio independiente a la tipología de los ajuares funerarios para explorar la cronología de sus manifestaciones más antiguas. El conjunto de dataciones que presentamos en este trabajo supone un salto cualitativo, pero es claramente insuficiente. Así, las valoraciones que siguen deben considerarse como una aproximación.

El análisis de la serie radiocarbónica a partir de diferentes modelados estadísticos permite establecer que el inicio de la actividad funeraria en el denominado "Grupo Puchena" ocurriría entre el 3845-3550 cal BC (95\% de probabilidad), posiblemente entre el $3730-3650$ cal BC $(68 \%$ de probabilidad). No parece haber entre los dos tipos de sepulturas analizados diferencias cronológicas significativas en sus inicios. La cronología de rundgräber y sepulturas de cámara y corredor es parecida, quizás ligeramente más antigua en las segundas, aunque las contadas dataciones para estos momentos aconseja prudencia en este sentido. La primera mitad de IV milenio parece, por tanto, la fecha más probable para el inicio del fenómeno megalítico en el sureste peninsular.

A partir de estos momentos, el paisaje del sureste comienza a monumentalizarse mediante la construcción de sepulturas y necrópolis que supusieron un cambio sustancial en las formas de comprensión de la realidad de las comunida- 
des que las erigieron. Las sociedades neolíticas por primera vez se atrevieron a modificar y a "humanizar" un orden natural considerado hasta entonces como sagrado y por tanto inalterable. El carácter duradero de estos monumentos junto a su visibilidad paisajística sugieren que posiblemente una de las motivaciones fundamentales para su construcción fuera el deseo de transcender el presente, creando un sentido de linealidad temporal donde pasado y futuro alcanzaron una relevancia previamente desconocida. De esta forma, las categorías de espacio y tiempo experimentaron un cambio de enorme relevancia, clave para la comprensión de las transformaciones sociales que se produjeron en el sureste. Así, estas sepulturas megalíticas supusieron la expresión de un nuevo orden social y cultural donde la memoria colectiva queda íntimamente vinculada a un paisaje que se ordena a través de su existencia.

Este proceso parece que tuvo dos fases claramente diferenciadas. Durante el IV milenio la construcción de sepulturas y la actividad funeraria asociada fue de baja intensidad si atendemos al número de mediciones radiométricas disponibles. Esta situación cambia a partir de inicios del III milenio, ya en época calcolítica, cuando se produce una clara intensificación del fenómeno megalítico. En estos momentos, junto a la continuidad en el uso funerario de sepulturas de época neolítica, caso de Las Churuletas 3, se produciría la construcción de nuevas sepulturas ${ }^{14}$, como la de La Atalaya 6, e incluso de nuevas necrópolis como Llano del Jautón, que concentra todos sus enterramientos en la primera mitad del III milenio. A ello habría además que sumar la aparición de los tholoi, un nuevo tipo de sepultura característico de las Edades del Cobre y Bronce (Aranda Jiménez y Lozano Medina 2014; Aranda Jiménez et al. 2017a). Es, por tanto, en la Edad del Cobre cuando el proceso de monumentalización adquirió su máximo desarrollo incrementándose la actividad funeraria de forma exponencial.

La coincidencia cronológica entre este fenómeno y el desarrollo del poblamiento durante el III milenio permite avanzar nuevas consideraciones. El incremento en el número de poblados durante

\footnotetext{
${ }^{14}$ Asumimos que, en general, las prácticas funerarias tuvieron lugar tras la construcción de las sepulturas y que las deposiciones más antiguas guardan una proximidad cronológica con este evento.
}

la Edad del Cobre ha sido tradicionalmente relacionado con un importante desarrollo demográfico (véanse las estimaciones demográficas realizadas para el área de estudio por Chapman 1991 y Castro et al. 1998). De forma paralela, los nuevos poblados se caracterizan por unas mayores dimensiones y estabilidad resultado de la consolidación del proceso de sedentarización y, posiblemente, de agregación poblacional. Frente a la movilidad que parece caracterizó a las poblaciones durante buena parte del periodo neolítico, ahora se produciría un cambio en las estrategias de poblamiento que supondría una cada vez mayor identificación de los grupos sociales con territorios concretos. En este contexto, la intensificación del fenómeno megalítico como medio para construir una memoria colectiva que ordena y da un nuevo significado al paisaje con el que se interacciona adquiere pleno sentido.

Según la serie radiocarbónica, el final de las prácticas funerarias ocurría entre el 2435-2190 cal BC (95\% de probabilidad), posiblemente entre el $2395-2270$ cal BC (68\% de probabilidad), aunque con importantes diferencias dependiendo del tipo de sepultura. El final de los rundgräber se produciría entre el 2650-2505 cal BC (68\% de probabilidad) y son en realidad las tumbas de cámara y corredor las que prolongan su actividad funeraria hasta el intervalo 2355-2155 cal BC (68\% de probabilidad). Quedaría pendiente la datación de sepulturas tipo tholos en el área anteriormente analizada. Si atendemos a la serie radiocarbónica obtenida para la necrópolis de El Barranquete (Níjar, Almería) es previsible la continuidad del fenómeno megalítico durante la Edad del Bronce, en especial en el periodo argárico (Aranda Jiménez y Lozano Medina 2014; Aranda Jiménez et al. 2017a).

En el caso de los rundgräber y de las tumbas de cámara y corredor, la actividad ritual y funeraria tampoco parece que se detuviera en los últimos siglos del III milenio cal BC. La serie radiocarbónica del "Grupo Purchena" no reflejaría las prácticas de reutilización de algunas de estas sepulturas durante el Bronce Final, caso de La Atalaya 8, o en la cuenca de Vera de sepulturas como La Encantada 1, Loma de la Gorriquía 1, Loma de los Caporchanes 2 o Loma del Campo de Mojácar 4, entre otras (Lorrio 2008). Además de la tipología de los materiales, varias dataciones radiocarbónicas realizadas sobre hueso humano

Trab. Prehist., 74, N. ${ }^{\circ}$ 2, julio-diciembre 2017, pp. 257-277, ISSN: 0082-5638

doi: $10.3989 /$ tp.2017.12194 
no solo confirmarían la reutilización durante el Bronce Final, caso de La Encantada 1 (CSIC$249,2830 \pm 60 \mathrm{BP} ; 1080-900$ cal BC a $1 \sigma$ ), sino también durante la Edad del Hierro, caso de Loma de La Gorriquía 1 (Beta-184196, 2300 \pm 40 BP; 410-255 cal BC a $1 \sigma$ ), e incluso en época histórica, caso de la Loma de Las Alparatas 1 (Beta$171806,1450 \pm 50 \mathrm{BP} ; 570-640$ cal AD a $1 \sigma)$ y de la Loma de los Caporchanes 2 (Beta-171807, $1850 \pm 50$ BP; 80-240 cal AD a $1 \sigma$ ) (Lorrio y Montero 2004). Parece, por tanto, evidente que la temporalidad del fenómeno megalítico está lejos de ser resuelta. Solo mediante el desarrollo de nuevos programas de dataciones que profundicen en el "Grupo Purchena" y se extiendan a las necrópolis de la Depresión de Vera será posible construir una cronología robusta que permita comprender la complejidad de este fenómeno.

\section{AGRADECIMIENTOS}

Al Museo Arqueológico Nacional (Madrid) y, en especial, a Carmen Cacho Quesada por facilitarnos el estudio de los materiales de la Colección Siret.

\section{BIBLIOGRAFÍA}

Acosta, C. y Cruz-Auñon, R. 1981: "Los enterramientos de las fases iniciales en la Cultura de Almería". Habis 12: 275-360.

Aitchison, T.; Ottaway, B. y Al-Ruzaiza, A. S. 1991: "Summarizing a group of $\mathrm{C} 14$ dates on the historical time scale: with a worked example from the Late Neolithic of Bavaria". Antiquity 65: 108-116.

Almagro Gorbea, M. 1972: "Nuevas fechas para la Prehistoria y la Arqueología peninsulares". Trabajos de Prehistoria 29: 228-244.

Alonso Mathias, J.; Cabrera Valdés, V.; Chapa Brunet, T. y Fernández-Miranda, y M. 1978: "Índice de fechas arqueológicas de C-14 para España y Portugal". En M. Almagro Gorbea y M. FernándezMiranda (eds.): C14 y Prehistoria de la Península Ibérica. Fundación Juan March, Madrid: 155-183.

Aranda Jiménez, G. 2013: “Against uniformity cultural diversity: The 'Others' in Argaric Societies". En M. Cruz Berrocal, L. García Sanjuán y A. Gilman (eds.): The Prehistory of Iberia. Debating Early Social Stratification and the State. Routledge. Nueva York: 99-118.
Aranda Jiménez, G. 2014: “La memoria como forma de resistencia cultural. Continuidad y reutilización de espacios funerarios colectivos en época argárica". En E. García Alfonso (ed.): Movilidad, contacto y cambio. II Congreso de Prehistoria de Andalucía (Antequera 2012): 255-277. Sevilla.

Aranda Jiménez, G. y Lozano Medina, A. 2014: "The chronology of megalithic funerary practices: a Bayesian approach to Grave 11 at El Barranquete necropolis (Almería, Spain)". Journal of Archaeological Science 50: 369-382.

Aranda Jiménez, G., Lozano Medina, A., Díaz-Zorita Bonilla, M. Sánchez Romero, M. y Escudero Carrillo, J. 2017a: "Cultural continuity and social resistance: the chronology of the megalithic funerary practices in southern Iberia". European Journal of Archaeology

Aranda Jiménez, G.; Lozano, J. A. y Pérez Valera, F. 2017b: "The Megalithic Necropolis of Panoria, Granada, Spain. Geoarchaeological characterization and provenance studies". Geoarchaeology. https://doi.org/10.1002/gea.21643

Aranda Jiménez, G.; Montón-Subias, S. y Sánchez Romero, M. 2015: The Archaeology of Bronze Age Iberia. Argaric societies. Routledge. Nueva York.

Bayliss, A. 2009: "Rolling out revolution: using radiocarbon dating in Archaeology". Radiocarbon 51(1): 123-177.

Bayliss, A.; Bronk Ramsey, C.; van der Plicht, J. y Whittle, A. 2007: "Bradshaw and Bayes: towards a timetable for the Neolithic". Cambridge Archaeological Journal 17 (1): 1-28.

Bayliss, A. y Whittle, A. E. (eds.) 2007: Histories of the dead: building chronologies for five southern British long barrows. Cambridge Archaeological Journal 17 (S1).

Benavides López, J. A.; Aranda Jiménez, G.; Sánchez Romero, M.; Alarcón García, E.; Fernández Martín, S.; Lozano Medina, A. y Esquivel Guerrero, J. A. 2016: "3D modelling in archaeology: the application of Structure from Motion methods to the study of the megalithic necropolis of Panoria (Granada, Spain)". Journal of Archaeological Science: Reports 10: 495-506.

Blance, B. 1961: "Early Bronze Age Colonists in Iberia". Antiquity 35: 192-202.

Bonani, G.; Beer, J.; Hofmann, H.; Synal, H. A.; Suter, M.; Wölfli, W.; Pfleiderer, C.; Kromer, B.; Junghans, C. y Münnich, K. O. 1987: "Fractionation, precision and accuracy in ${ }^{14} \mathrm{C}$ and ${ }^{13} \mathrm{C}$ measurements". Nuclear Instruments and Methods in Physics Research Section B: Beam Interactions with Materials and Atoms 29, 1-2: 87-90.

Bosch Gimpera, P. 1932: Etnologia de la Península Ibèrica. Editorial Alpha. Barcelona.

Bosch Gimpera, P. 1944: El poblamiento antiguo y la formación de los pueblos de España. Imprenta Universitaria. México. 
Bosch Gimpera, P. 1969: "La cultura de Almería". Pyrenae 5: 47-93.

Bronk Ramsey, C. 1994: "Analysis of chronological information and radiocarbon calibration: the program OxCal". Archaeological Computing Newsletter 41: 11-6.

Bronk Ramsey, C. 1995: "Radiocarbon calibration and analysis of stratigraphy: the OxCal program". $R a$ diocarbon 37 (2): 425-430.

Bronk Ramsey, C. 2001: "Development of the radiocarbon calibration program". Radiocarbon 43(2): 355-363.

Bronk Ramsey, C. 2009: "Bayesian Analysis of radiocarbon dates". Radiocarbon 51(1): 337-360.

Buck, C. E.; Cavanagh, W. G. y Litton, C. D. 1996: Bayesian approach to interpreting archaeological data. Wiley. Chichester.

Buck, C. E.; Kenworthy, J.; Litton, C. D. y Smith, A. F. M. 1991: "Combining archaeological and radiocarbon information: a Bayesian approach to calibration". Antiquity 65: 808-821.

Camalich Massieu, M. D. 1983. "La cerámica eneolítica no campaniforme de Andalucía Sudoriental". Anuario 81-82. Sección de Derecho, Geografía e Historia, I. Servicio de Publicaciones de la Universidad de La Laguna. La Laguna: 133-217.

Camalich Massieu, M. D. y Martín Socas, D. (eds.) 1999: El territorio almeriense desde los inicios de la producción hasta fines de la antigüedad. Un modelo: la depresión de Vera y cuenca del río Almanzora. Consejería de Cultura de la Junta de Andalucía. Sevilla.

Camalich Massieu, M. D. y Martín Socas, D. 2013: "Los inicios del Neolítico en Andalucía. Entre la tradición y la innovación". Menga. Revista de Prehistoria de Andalucía 4: 103-129.

Camalich Massieu, M. D.; Martín-Socas, D.; Casasús Latorre, L. y González Quintero, P. 1989: "Pottery group of Purchena (Almería, Spain): a cluster analysis". Archaeometry. Elsevier. Amsterdam: 603-612.

Cámara Serrano, J. A. y Molina González, F. 2004: "El megalitismo en el sureste de la Península Ibérica. Ideología y control territorial". Mainake XXVI: 139-163.

Castaño, P. ; Delibes, G. ; Fernández-Miranda, M.; Fernández-Posse, M. ${ }^{a}$ D.; Mariscal, B.; Martín, C.; Montero, I. y Rovira, S. 1991: "Applications des méthodes archéometriques pour l'analyse du Chalcolithique dans le bassin de Vera (Almería, España)". Révue d'Archéometrie 15: 47-53.

Castro, P.; Chapman, R.; Gili, S.; Lull, V.; Micó, R.; Rihuete, C.; Risch, R. y Sanahuja, E. (eds.) 1998: Aguas Project - Palaeoclimatic reconstruction and the dynamics of human settlement and land-use in the area of the middle Aguas (Almeria) of the south-east of the Iberian Peninsula. Luxembourg Publications of the European Comission: Science, Research and Development. Luxemburgo.
Chapman, R. 1991: La formación de las sociedades complejas. El sureste de la península ibérica en el marco del Mediterráneo Occidental. Crítica. Barcelona.

Delibes, G.; Díaz-Andreu, M.; Fernández-Posse, M. ${ }^{a}$ D.; Montero, I.; Muñoz, I. K. y Ruiz, A. 1996: "Poblamiento y desarrollo cultural en la Cuenca de Vera durante la Prehistoria Reciente". En M. A. Querol y T. Chapa (eds.): Homenaje al profesor Manuel Fernandez-Miranda. Complutum Extra 6 (I): 153-170.

Díaz-Zorita Bonilla, M.; Aranda Jiménez, G.; Escudero Carrillo, J.; Robles Carrasco, S.; Lozano Medina, A.; Sánchez Romero, M. y Alarcón García, E. 2016: "Estudio bioarqueológico de la necrópolis megalítica de El Barranquete (Níjar, Almería)". Menga. Revista de Prehistoria de Andalucía 7: 71-98.

Dunbar, E.; Cook, G. T.; Naysmith, P.; Tripney, B. G. y $\mathrm{Xu}$, S. 2016: "AMS 14C dating at the Scottish Universities Environmental Research Centre (SUERC) Radiocarbon Dating Laboratory". Radiocarbon 58 (1): 9-23.

Guilaine, J. 1996: "Proto-megalithisme, rites funeraires et mobiliers de prestige néolithiques en Méditerranée Occidentale". En M. a A. Querol y T. Chapa (eds.) : Homenaje al profesor Manuel FernandezMiranda. Complutum Extra 6 (I): 123-140.

Hajdas, I. 2008: "Radiocarbon dating and its application in Quaternary studies". Eiszeitalter und Gegenwart 57 (1-2): 2-24.

Leisner, G. y Leisner, V. 1943: Die Megalithgraber der Iberischen Halbinsel: Der Suden. Walter de Gruyter. Berlín.

Lorrio Alvarado, A. J. 2008: Qurénima. El Bronce Final del Sureste de la Península Ibérica. Real Academia de la Historia, Universidad de Alicante. Madrid.

Lorrio Alvarado, A. J. y Montero Ruiz, I. 2004: "Reutilización de sepulcros colectivos en el sureste de la Península Ibérica: la colección Siret”. Trabajos de Prehistoria 61 (1): 99-116.

Lozano Medina, A. y Aranda Jiménez, G. 2017: "La temporalidad de las sepulturas megalíticas tipo Tholos del sur de la Península Ibérica". Spal. Revista de Prehistoria y Arqueología 26: 17-31.

Maicas Ramos, R. 1997: "Excavando en los museos: El Llano de la Lámpara". Boletín del Museo Arqueológico Nacional XV (1 y 2): 5-24.

Maicas Ramos, R. 2005: "Rituales de enterramiento en la cuenca del Vera". En P. Arias Cabal, R. Ontañón Peredo y C. García-Moncó Piñeiro (eds.): Actas del III Congreso del Neolítico en la Península Ibérica (Santander 2003): 767-774. Santander.

Maicas Ramos, R. 2007: Industria ósea y funcionalidad: Neolítico y Calcolítico en la Cuenca de Vera (Almería). Bibliotheca Praehistorica Hispana 24, Consejo Superior de Investigaciones Científicas. Madrid.

Maicas Ramos, R. y Papí, C. 2008: “Facta non ver$b a$. Estudio preliminar del Archivo Siret del Museo 
Arqueológico Nacional: principales documentos arqueológicos". En G. Mora, C. Papí y M. Ayarzaguena (eds.): Documentos inéditos para la Historia de la Arqueología. Sociedad Española de Historia de la Arqueología. Madrid: 49-66.

Martín-Socas, D.; Camalich Massieu, M. D.; Tejedor Salguero, M. L. y Rodríguez Rodríguez, A. 1989: "Mineralogical composition and evaluation of firing temperaturas of the Purchena pottery (Almería, Spain)". En Y. Maniatis (ed.). Archaeometry. Proceedings of the $25^{\text {th }}$ International Symposium (Athens 1986). Elsevier. Amsterdam, Oxford, Nueva York, Tokio: 149-157.

Mederos, A. 1995: "La cronología absoluta de la Prehistoria Reciente del sureste de la Península Ibérica". Pyrenae 26: 53-90.

Michczyńsky, A. y Michczyńsky, D. J. 2006: “The effect of pdf peaks' height increase during calibration of radiocarbon date sets". Geochronometria. Journal on Methods and applications of Absolute Chronology 25: 1-4.

Montero Ruiz, I.; Rihuete Herrada, C. y Ruiz-Taboada, A. 1999: "Precisiones sobre el enterramiento colectivo Neolítico de Cerro Virtud (Cuevas del Almanzora, Almería)". Trabajos de Prehistoria 56 (1): 119-130.

Murillo Barroso, M.; Martinón-Torres, M.; Cámalich Massieu, M. D.; Martín Socas, D. y Molina González, F. 2017: "Early metallurgy in SE Iberia. The workshop of Las Pilas (Mojácar, Almería, Spain)". Archaeological and Anthropological Science, DOI: 10.1007/s12520-016-0451-8.

Olaria, C. 1977: "Excavaciones en la necrópolis megalítica de las Churuletas (Purchena, Almería)". Actas del XIV Congreso Nacional de Arqueología (Vitoria 1975): 439-452. Zaragoza.

Ottaway, B. 1973: "Estimating the duration of cultures". Antiquity 47: 231-233.

Peña y Montes de Oca, C. de la 1986: "La necrópolis de Los Churuletes (Purchena, Almería)". Cuadernos de Prehistoria de la Universidad de Granada 11: 73-170.

Peña Romo, V. 2011: "Excavando huesos en los museos. El caso de la necrópolis de "Los Millares"". En A. González Martín, O. Cambra-Moo, J. Rascón Pérez, M. Campo Martín, M. Robledo Acinas, E. Labajo González y J. A. Sánchez Sánchez (eds.): Paleopatología: ciencia multidisciplinar. Sociedad Española de Paleopatología. Madrid: 73-89.

Reimer, P. J. y McCormac, F. G. 2002: "Marine radiocarbon reservoir correction for the Mediterranean and Aegean seas". Radiocarbon 44 (1): 159-166.
Reverte Coma, J. M. 1986: "Estudio antropológico y paleontológico de restos óseos del yacimiento de Los Churuletes (Purchena, Almería)". Cuadernos de Prehistoria de la Universidad de Granada 11: 157-161.

Román Díaz, M. P.; Martínez, C.; López, M. J.; Suárez, N.; Pérez, A. D. y Aguayo, P. 2000: "Proyecto: estudio del proceso histórico durante la Prehistoria y Antigüedad en la cuenca del Alto Almanzora (Almería)". Anales de Arqueología Cordobesa 11: 32-52.

Román Díaz, M. P.; Martínez Padilla, C.; Sánchez Quirante, L.; Pérez, A. D. y Cassinello, S. 1996: "El Neolítico en la Cuenca Alta del Río Almanzora". Actes del I Congrés del Neolític a la Península Ibérica. Formació i implantació de les comunitats agrícolas (Gavà-Bellaterra 1995). Rubricatum: revista del Museu de Gavà 1 (2): 613-618.

Ruiz-Taboada, A. y Montero Ruiz, I. 1999: “Ocupaciones neolíticas en Cerro Virtud: Estratigrafía y Dataciones". II Congrés del Neolític a la Península Ibèrica (Valencia 1999). Saguntum Extra 2: 207211.

Scarre, C. 2010: "Rocks of ages: tempo and time in megalithic monuments". European Journal of Archaeology 13 (2): 175-193.

Stuiver, M.A. y Polach, H.A. 1977. "Reporting of 14C Data". Radiocarbon 19: 355-363.

Synal, H. A.; Bonani, G.; Döbeli, M.; Ender, R. M.; Gartenmann, P.; Kubik, P. W.; Schnabel, C. y Suter, M. 1997: "Status report of the PSI/ETH AMS facility". Nuclear Instruments \& Methods in Physics Research Section B: Beam Interactions with Materials and Atoms 123, 1-4: 62-68.

Synal, H. A.; Stocker, M. y Suter, M. 2007: "MICADAS: A new compact radiocarbon AMS system". Nuclear Instruments and Methods in Physics Research Section B-Beam Interactions with Materials and Atoms, Accelerator Mass Spectrometry 259, 1: 7-13.

Taylor, R. E. 1997: “Radiocarbon dating”. En R. E. Taylor y M. J. Aitken (eds.): Chronometric Dating in Archaeology. Plenum Press. Nueva York.

Ward, G. K. y Wilson, S. R. 1978: "Procedures for comparing and combining radiocarbon age determinations: a critique". Archaeometry 20 (1): 19-31.

Whittle, A.; Bayliss, A. y Healy, F. 2008: "The timing and tempo of change: examples from the fourth millennium cal BC in Southern England". Cambridge Archaeological Journal 18 (1): 65-70.

Whittle, A.; Healy, F. y Bayliss, A. 2011: Gathering time: dating the early Neolithic enclosures of southern Britain and Ireland. Oxbow books. Oxford. 